\title{
Lidar characterization of the Arctic atmosphere during ASTAR 2007: four cases studies of boundary layer, mixed-phase and multi-layer clouds
}

\author{
A. Lampert ${ }^{1}$, C. Ritter $^{1}$, A. Hoffmann ${ }^{1}$, J.-F. Gayet ${ }^{2}$, G. Mioche ${ }^{2}$, A. Ehrlich ${ }^{3,{ }^{*}}$, A. Dörnbrack ${ }^{4}$, M. Wendisch ${ }^{3, *}$, and \\ M. Shiobara ${ }^{5}$ \\ ${ }^{1}$ Alfred Wegener Institute for Polar and Marine Research, 14473 Potsdam, Germany \\ ${ }^{2}$ Laboratoire de Météorologie Physique UMR 6016 CNRS/Université Blaise Pascal, France \\ ${ }^{3}$ Johannes Gutenberg-University Mainz, Institute for Atmospheric Physics, 55099 Mainz, Germany \\ ${ }^{4}$ Institute of Atmospheric Physics, DLR Oberpfaffenhofen, 82234 Oberpfaffenhofen, Germany \\ ${ }^{5}$ National Institute of Polar Research, Tokyo 190-8518, Japan \\ * ${ }^{*}$ ow at: Leipzig Institute for Meteorology (LIM), University of Leipzig, 04109 Leipzig, Germany
}

Received: 28 June 2009 - Published in Atmos. Chem. Phys. Discuss.: 13 July 2009

Revised: 3 March 2010 - Accepted: 12 March 2010 - Published: 26 March 2010

\begin{abstract}
During the Arctic Study of Tropospheric Aerosol, Clouds and Radiation (ASTAR), which was conducted in Svalbard in March and April 2007, tropospheric Arctic clouds were observed with two ground-based backscatter lidar systems (micro pulse lidar and Raman lidar) and with an airborne elastic lidar. In the time period of the ASTAR 2007 campaign, an increase in low-level cloud cover (cloud tops below $2.5 \mathrm{~km}$ ) from $51 \%$ to $65 \%$ was observed above Ny-Ålesund. Four different case studies of lidar cloud observations are analyzed: With the ground-based Raman lidar, a layer of spherical particles was observed at an altitude of $2 \mathrm{~km}$ after the dissolution of a cloud. The layer probably consisted of small hydrated aerosol (radius of $280 \mathrm{~nm}$ ) with a high number concentration (around $300 \mathrm{~cm}^{-3}$ ) at low temperatures $\left(-30^{\circ} \mathrm{C}\right)$. Observations of a boundary layer mixedphase cloud by airborne lidar and concurrent airborne in situ and spectral solar radiation sensors revealed the localized process of total glaciation at the boundary of different air masses. In the free troposphere, a cloud composed of various ice layers with very different optical properties was detected by the Raman lidar, suggesting large differences of ice crystal size, shape and habit. Further, a mixed-phase double layer cloud was observed by airborne lidar in the free troposphere. Local orography influenced the evolution of this cloud. The four case studies revealed relations of cloud properties and specific atmospheric conditions, which we plan to use as the base for numerical simulations of these clouds.
\end{abstract}

Correspondence to: A. Lampert

(astrid.lampert@awi.de)

\section{Introduction}

The Arctic is a sensitive indicator of climate change due to a large number of special interactions and feedback mechanisms (Curry et al., 1996). Therefore, data collection by ground-based and airborne experiments in this remote region is important (IPCC, 2007). Of all atmospheric constituents, water is the most variable in space and time and occurs in all three thermodynamic phases. The liquid and solid phase can occur as clouds, which have a significant influence on the solar and terrestrial radiation budget. The formation, evolution and dissipation of tropospheric clouds in the Arctic are not yet entirely understood. Unique Arctic cloud characteristics include the occurrence of liquid and mixed-phase clouds at temperatures down to $-34^{\circ} \mathrm{C}$ (Intrieri et al., 2002a; Turner, 2005) and the formation of multiple cloud layers (Verlinde et al., 2007; Luo et al., 2008). Multiple layers of predominantly liquid droplets are observed regularly in the summer boundary layer, but have been reported seldom in the free troposphere. Further, optically thin clouds occur frequently in winter time. They cause large differences in cloud cover observed by sensitive lidar/radar measurements, satellite cloud retrieval and human observers (Wyser and Jones, 2005).

The average cloud cover in the Arctic is generally high. E.g. during the one-year observations of the Surface Heat Budget of the Arctic Ocean experiment (SHEBA, Intrieri et al., 2002a), it was found to be $85 \%$. About $73 \%$ of these cases contained at least some liquid water clouds (Intrieri et al., 2002a). Liquid water occurred up to altitudes of $6.5 \mathrm{~km}$ (Intrieri et al., 2002a). 
Gayet et al. (2007) observed the feeder-seeder effect, i.e. ice crystals and drizzle particles falling out of a cirrus cloud layer into a stratiform layer of liquid cloud droplets. This effect can lead to local glaciation of low level clouds with subsequent precipitation of ice crystals and cloud dissipation (Campbell and Shiobara, 2008).

Mixed-phase clouds are composed of both liquid water droplets and ice crystals. The characteristic vertical structure consists of an upper layer dominated by liquid water droplets and a layer of ice crystals below (e.g. Pinto, 1998; Shupe et al., 2008; Gayet et al., 2009; Ehrlich et al., 2009). Processes in mixed-phase clouds, ensuring their persistence over days and sometimes weeks, are still poorly understood (e.g. Harrington et al., 1999; Morrison et al., 2008). Their life time critically depends on temperature, ice concentration, the habit of the ice crystals (Harrington et al., 1999) as well as the number of ice forming nuclei (Jiang et al., 2000; Morrison et al., 2008). Otherwise, the predominantly liquid clouds dissipate quickly if the ice concentration gets too high and the ice crystals grow at the expense of the liquid water droplets (Wegener-Bergeron-Findeisen process, Wegener, 1911; Bergeron, 1935; Findeisen, 1938). Mixed-phase clouds occur frequently in the Arctic from spring to fall (Intrieri et al., 2002a) and are especially challenging to describe and parameterize (e.g. Harrington et al., 1999; Morrison et al., 2008). Their impact on the surface radiation balance is difficult to quantify as liquid and solid cloud phases generally show different scattering properties (McFarquhar and Cober, 2004).

For most of the year, Arctic clouds have a total net warming effect on the surface radiation balance (Curry et al., 1993; Intrieri et al., 2002b), with a mean additional irradiance estimated as $30 \mathrm{~W} \mathrm{~m}^{-2}$ by Intrieri et al. (2002b) and $40-50 \mathrm{~W} \mathrm{~m}^{-2}$ by Curry et al. (1996). However, the local and temporary radiative forcing of mixed-phase clouds may differ significantly depending on solar zenith angle, surface albedo, cloud geometry, cloud optical thickness and the partitioning of liquid and ice water in the clouds (Harrington, 1999; Vavrus, 2004). Ehrlich (2009) estimated a surface cooling of $-160 \mathrm{~W} \mathrm{~m}^{-2}$ for boundary layer pure liquid water clouds with an optical thickness of about 15 overlaying open ocean (surface albedo of 0.1 , solar zenith angle of $71^{\circ}$ ).

Clouds have been investigated in a number of campaigns in the North American part of the Arctic: Mixed-Phase Arctic Cloud Experiment, M-PACE, in fall 2004 (Verlinde et al., 2007); First International Satellite Cloud Climatology Project Regional Experiment Arctic Cloud Experiment, FIRE ACE, in May/July 1998 (Curry et al., 2000; Lawson et al., 2001); SHEBA in 1997-1998 (Intrieri et al., 2002, Turner, 2005); Beaufort and Arctic Storms Experiment, BASE, in September/October 1994 (Curry et al., 1997, Pinto et al., 1998). Similar extensive ground-based and airborne data sets of clouds in the European Arctic are missing. Here, few studies of mixed-phase clouds have been performed during the Arctic Study of Tropospheric Aerosol,
Clouds and Radiation (ASTAR) near Spitsbergen in June 2004 and March/April 2007 (Gayet et al., 2007, 2009). Further, Arctic clouds were studied during the Polar Study using Aircraft, Remote Sensing, Surface Measurements and Models, of Climate, Chemistry, Aerosols, and Transport (POLARCAT) campaigns from Northern Sweden in April 2008 and Greenland in July 2008 (Law et al., 2008). Due to different possible pollution pathways (Stohl, 2006) and different ambient conditions (especially the western part of Spitsbergen being warm for its location, caused by the influence of the North Atlantic Current) it is not clear whether findings from the North American part of the Arctic can be applied there.

The Arctic troposphere is also subject to other phenomena such as Arctic haze (Quinn et al., 2007), diamond dust (Intrieri and Shupe, 2004), and blowing snow (Dörnbrack et al., 2010). Arctic haze consists of anthropogenic aerosol transported into the Arctic region in spring time from polluting sources at southern latitudes. It can reach high optical depth values up to 0.3 at $532 \mathrm{~nm}$ wavelength over Spitsbergen (Herber et al., 2002) and thus significantly influences the radiation budget (e.g. Blanchet and List, 1983; Rinke et al., 2004; Quinn et al., 2007, and references therein). According to the IPCC report (IPCC, 2007), it is still difficult to quantify precisely the radiative forcing and the interaction of aerosol with clouds in the Arctic. Diamond dust is the ice precipitation out of "cloudless" sky, and is often observed in winter time. It was found to have a negligible radiative effect (Intrieri and Shupe, 2004). Blowing snow is usually confined to the lowest few $100 \mathrm{~m}$ above ground, depending on the surrounding topography of a location, and can significantly increase the downward infrared irradiance (e.g. Lesins et al., 2009).

The current cloud parameterizations applied in most regional climate models (e.g. the High-Resolution (Hamburg) Limited-Area Model, HIRHAM4, Christensen et al., 1996), weather prediction models (e.g. the model of the European Centre for Medium-Range Weather Forecasts, ECMWF), as well as general circulation models (e.g. the National Center for Atmospheric Research Community Climate System Model, NCAR CCSM3, Collins et al., 2006) diagnose the liquid and ice fraction of clouds as a function of temperature. As a consequence, the frequently observed existence of liquid droplets at temperatures below $255 \mathrm{~K}\left(-18^{\circ} \mathrm{C}\right.$, e.g. Turner, 2005) is underestimated by regional climate models (Sandvik et al., 2007), weather prediction models (Gayet et al., 2009) and general circulation models (Vavrus, 2004). Measurements show that mixed-phase clouds cannot always be represented adequately by a temperature proxy alone (Pinto et al., 2001; Korolev et al., 2003; Boudala et al., 2004; Mc Farquhar et al., 2007). Models are not able to reproduce the observed Arctic cloud cover (Wyser et al., 2008). Therefore, deeper investigation of Arctic clouds is needed.

In this article we present case studies of tropospheric Arctic clouds observed by lidar technique during the ASTAR 2007 campaign and analyze them in the context of the 
specific atmospheric conditions. Lidar systems provide horizontal and vertical cloud structure information at high spatial and temporal resolution. The basic information about cloud altitude is essential for understanding cloud formation and evolution processes as well as for radiative transfer studies (Shupe and Intrieri, 2004) and climate modeling (Inoue et al., 2006). A depolarization lidar enables to retrieve the thermodynamic phase of the cloud layer closest to the lidar system. Cloud phase plays a crucial role for the surface energy budget (McFarquhar and Cober, 2004). Further, Raman lidar measurements provide the lidar ratio (extinction to backscatter ratio), which gives information about internal processes in clouds (e.g. the growth/shrinking of small-size cloud particles).

Section 2 introduces the lidar systems and additional airborne instrumentation. The results and analyses of the cloud observations are presented in Sect. 3. A statistical overview of cloud occurrence and height distribution in Ny-Ålesund (West coast of Spitsbergen at $78.9^{\circ} \mathrm{N}$ and $11.9^{\circ} \mathrm{E}$ ) is presented, followed by a detailed analysis of four case studies of cloud observations. The first two cases A and B describe clouds in the boundary layer, and the other two cases $\mathrm{C}$ and $\mathrm{D}$ clouds in the free troposphere. Section 4 presents the summary underlining the new aspects of the observed cloud cases and pointing out the connection with the atmospheric conditions.

\section{Instruments and data}

Three lidar systems were deployed for the following specific purposes: The ground-based micro pulse lidar (MPL) provided continuous backscatter information on cloud structures $24 \mathrm{~h}$ per day. The ground-based Koldewey Aerosol Raman Lidar (KARL) served to determine the backscatter and extinction coefficients as well as the depolarization for optically thin clouds. Both lidar systems were situated in NyÅlesund. The Airborne Mobile Aerosol Lidar (AMALi), operating in either nadir or zenith viewing direction on board of the Do-228 research aircraft "Polar-2", was utilized to obtain the backscatter coefficient and depolarization ratio for tropospheric clouds over the Arctic Ocean. The technical specifications of the three lidar systems, including the typical vertical and temporal resolutions of each instrument, are given in Table 1. While the stationary lidar systems provide information on the temporal development combined with the movement of the cloud, the airborne lidar gives a quasiinstantaneous snapshot of cloud structures along the flight track.

\subsection{Micro Pulse Lidar}

The micro pulse lidar (MPL) is a compact and eye-safe lidar system for the acquisition of long-term data of particle backscatter profiles on a 24-h basis (Spinhirne, 1993). The
Table 1. Technical specifications of the three lidar systems and resolution of the data used for this study.

\begin{tabular}{llll}
\hline & MPL & KARL & AMALi \\
\hline laser & Nd:YLF & Nd:YAG & Nd:YAG \\
emitted wavelengths [nm] & 523 & $1064,532,355$ & 532,355 \\
detected wavelengths [nm] & 523 & $1064,532,355$ & 532,355 \\
& & $387,407,607,660$ & \\
telescope diameter [cm] & 20 & 30 & 10.2 \\
FOV [mrad] & 0.10 & 0.83 & 3.1 \\
vertical resolution [m] & 30 & 60 & 7.5 \\
time resolution [s] & 600 & 600 & 15 \\
\hline
\end{tabular}

MPL in Ny-Ålesund is operated by the Japanese National Institute of Polar Research (NIPR) as a Micro-Pulse Lidar Network (MPLNET, Welton et al., 2001) site in the Arctic. It is maintained by the base personnel of the French-German research station AWIPEV (Alfred Wegener Institute/Institut Paul Emile Victor).

The system consists of a Nd:YLF laser with a wavelength of $523.5 \mathrm{~nm}$, a signal control unit, a Schmidt-Cassegrain telescope with $20 \mathrm{~cm}$ diameter for laser transmission and receiving and a computer for data acquisition. The data are acquired over a sampling range of $60 \mathrm{~km}$ with a vertical resolution of $30 \mathrm{~m}$ and a temporal average of $1 \mathrm{~min}$. The laser pulses are emitted vertically through a glass window. Data losses usually only occur when the window is covered with snow, which required to be removed manually.

For the MPL cloud cover statistics, cloud base and cloud top height were analyzed for the data from 15 March until 30 April 2007. First, the data were averaged to means of $10 \mathrm{~min}$, background corrected and cut above $21 \mathrm{~km}$. From the obtained profiles the total backscatter coefficient $\beta=\beta^{\text {Ray }}+$ $\beta^{\text {part }}$ was calculated with the Klett algorithm (Klett, 1985). $\beta^{\text {Ray }}$ and $\beta^{\text {part }}$ are the molecular Rayleigh and the particle backscatter coefficients, respectively. The backscattering ratio (BSR) for a given wavelength $\lambda$ at range $z$, defined as

$\operatorname{BSR}(\lambda, z)=\frac{\beta^{\text {Ray }}(\lambda, z)+\beta^{\text {part }}(\lambda, z)}{\beta^{\text {Ray }}(\lambda, z)}$,

is introduced to obtain values which can easily be compared to the clean atmosphere. In the case of pure Rayleigh scattering caused by the nitrogen and oxygen molecules in the air, the BSR has a value of 1 . Typical values for enhanced aerosol load are around 2, for optically thin clouds up to around 10 .

The algorithm for cloud detection compares the BSR values of adjacent height intervals. Different thresholds for BSR were used in order to categorise the clouds. E.g. the difference of adjacent BSR values had to show increasing values of more than 0.1 for at least 3 height steps or a single peak difference of minimal 0.2 if no lower clouds were detected. The BSR was analyzed for cloud peak structures in five distinct altitude intervals: 0-300 $\mathrm{m}$ (snow on the window), 300$1200 \mathrm{~m}$ (boundary layer clouds), 1200-2500 m (low clouds), 
2500-5500 m (midlevel clouds) and 5500-10000 m (high clouds). If none of these were detected the profile was set to "cloud free". The cloud categories take into account the frequent occurrence of two temperature inversions at around $1200 \mathrm{~m}$ and $2500 \mathrm{~m}$ altitude observed by radio sounding in Ny-Ålesund, which is influenced by local orography. The upper limit of midlevel clouds follows the definition of Pinto et al. (2001). Since the signal to noise ratio (SNR) above a cloud structure can decrease dramatically, the peak threshold conditions were adjusted accordingly (e.g. a SNR below 3 between 7.5 and $10 \mathrm{~km}$ and the detection of no clouds give evidence that there was snow on the window instead of a cloud free atmosphere). Depending on the optical thickness of the lower clouds, the data associated with a high cloud occurrence have to be considered less reliable.

\subsection{Koldewey Aerosol Raman Lidar}

The Koldewey Aerosol Raman Lidar (KARL), firmly integrated in the atmospheric observatory at Ny-Ålesund, measures aerosol, clouds and water vapor in the troposphere and aerosol in the stratosphere. In 2007 it consisted of a Spectra $\mathrm{Nd}$ :YAG laser emitting at the wavelengths $355 \mathrm{~nm}, 532 \mathrm{~nm}$ and $1064 \mathrm{~nm}$ simultaneously at a pulse repetition frequency of $50 \mathrm{~Hz}$ and a power of about $10 \mathrm{~W}$ per wavelength. The telescope of $30 \mathrm{~cm}$ diameter with $0.83 \mathrm{mrad}$ field of view (FOV) shows a complete overlap with the emitted laser beam above $1.2 \mathrm{~km}$. It collects, apart from the mentioned elastic wavelengths $(532 \mathrm{~nm}$ also in perpendicular state of polarization), the molecular nitrogen Raman shifted lines at $387 \mathrm{~nm}$ and $607 \mathrm{~nm}$, as well as the water vapor lines at $407 \mathrm{~nm}$ and $660 \mathrm{~nm}$. For the lowest atmospheric layers, a smaller mirror of $11 \mathrm{~cm}$ diameter with $2.25 \mathrm{mrad}$ FOV was used, which provided information above an altitude of $500 \mathrm{~m}$. In this range, only the wavelengths $532 \mathrm{~nm}, 607 \mathrm{~nm}$ and $660 \mathrm{~nm}$ were recorded. More details about the system and its applications can be found in Ritter et al. (2004). The error of the volume depolarization ratio is smaller than $\pm 5 \%$ for an altitude up to $6 \mathrm{~km}$. Combining the backscatter at 3 wavelengths and extinction at 2 wavelengths, KARL data can be used to estimate the index of refraction and the size distribution for spherical particles in the range between $0.1 \mu \mathrm{m}$ to $1.25 \mu \mathrm{m}$ following the method developed by Böckmann (2001).

The analysis of the lidar data was performed in the following steps: The elastic lidar profiles were averaged to a resolution of $10 \mathrm{~min}$ and $60 \mathrm{~m}$. As the retrieval of the extinction from remote sensing data is a mathematically ill-posed problem (Pornsawad et al., 2008) and any kind of smoothing would strongly affect the derived extinction, the extinction of the molecular nitrogen Raman signals at $387 \mathrm{~nm}$ and $607 \mathrm{~nm}$ were retrieved following the methodology of Ansmann et al. (1992) for completely unsmoothed lidar signals. Due to the inevitable noise in the data, the particle extinction coefficient was not calculated directly but rather its sum over the height interval containing the cloud of interest.
To determine the lidar ratio, we proceeded as follows: After the calculation of the layer integrated optical depth, the particle backscatter coefficient was calculated via the density profile from the radiosonde according to Ansmann et al. (1992). Finally, the lidar ratio of the cloud is the layer integrated optical depth divided by the layer integrated particle backscatter coefficient. Hence it constitutes an average value for the whole cloud.

The KARL and MPL lidar systems were compared for one particular day (21 April 2007, cloud C). For the same temporal and vertical resolution, a SNR of around 5 was obtained at $15 \mathrm{~km}$ altitude by KARL and at $5 \mathrm{~km}$ altitude by the MPL. Therefore, the KARL lidar is better suited for the observation of optically thin and high clouds. However, it cannot detect optically thick clouds if the detectors are saturated. In contrast, the MPL was designed in a way that also the observation of optically thick clouds is possible without damaging the detectors.

\subsection{Airborne Mobile Aerosol Lidar}

The Airborne Mobile Aerosol Lidar (AMALi) is an airborne backscatter lidar system operating at two wavelengths $(532 \mathrm{~nm}$ and $355 \mathrm{~nm})$. Additionally, it measures the linear volume depolarization of molecules and particles at $532 \mathrm{~nm}$. AMALi has been developed and operated by the Alfred Wegener Institute for Polar and Marine Research (Stachlewska et al., 2004; Lampert et al., 2009, and Stachlewska et al., 2009). AMALi can be installed in nadir or zenith viewing configuration onboard of AWI's Polar-2 aircraft. The real time display of the range corrected lidar signal offers the possibility to detect atmospheric structures of interest during the flight and guide the aircraft accordingly. In this paper, we focus on the signal at the wavelength of $532 \mathrm{~nm}$ in both polarization directions. No supplementary information was retrieved from the second wavelength of $355 \mathrm{~nm}$ considering cloud particles with diameter larger than the lidar wavelengths (effective diameter $>5 \mu \mathrm{m}$ ).

The minimum horizontal resolution was determined by a signal to noise ratio above 15 at cloud top in nadir and at cloud base in zenith configuration. For the cases presented here, the data were averaged over $15 \mathrm{~s}$. At the aircraft's ground speed of about $60 \mathrm{~m} \mathrm{~s}^{-1}$, the horizontal resolution was around $900 \mathrm{~m}$. The evaluation of the lidar data was done with the standard Klett algorithm (Klett, 1985). In the inversion algorithm, a value of the backscatter coefficient has to be assumed at the far end of the lidar profile. For the nadir measurements of boundary layer clouds, the value of the backscatter coefficient was set below the clouds and varied iteratively to obtain a reasonable backscatter coefficient above the cloud (Stachlewska et al., 2009). However, for optically thick clouds, it is not possible to derive accurate values of the cloud backscatter and extinction coefficients from the lidar measurements. Only qualitative information about the structure and the thermodynamic phase of the uppermost 
cloud layer can be obtained in this case. For the zenith measurements of the midlevel clouds, the fit value was set above the clouds and varied iteratively to obtain plausible values of the backscatter coefficient in the free troposphere below the cloud (Stachlewka et al., 2009). The air density profiles necessary for estimating the Rayleigh backscatter profiles were computed from meteorological data of the temporally closest radiosonde launched from the AWIPEV observatory in Ny-Ålesund.

Information from the depolarization channel has to be considered carefully. The depolarization of a pure water cloud consisting of spherical droplets is zero for a backscatter angle of $180^{\circ}$, but the depolarization value measured by a lidar system strongly depends on its FOV (Hu et al., 2001). As the FOV of the AMALi is rather large (3.1 mrad), multiple scattering affects the depolarization signal for clouds with an optical depth higher than 0.1. With increasing optical depth, the depolarization signal received from liquid clouds increases gradually from 0 to values in the range of non-spherical ice particles (e.g. a depolarization ratio of $30 \%$ at an optical depth of around 3 was calculated for the geometry of the Cloud-Aerosol Lidar with Orthogonal Polarization, CALIOP, You et al., 2006). For liquid water clouds, the backscatter and the depolarization are positively correlated, while for ice clouds, the depolarization decreases with penetration into the cloud, as was observed for CALIPSO data (Hu et al., 2006, 2007). Therefore, the slopes of individual AMALi profiles of backscatter and depolarization ratio were evaluated in order to distinguish whether a cloud layer consisted of liquid water droplets or ice particles.

\subsection{Additional airborne instruments}

\subsubsection{In situ measurements}

The different in situ instruments deployed onboard of the Polar-2 were operated by the Laboratoire de Météorologie Physique (LaMP). They included the Forward Scattering Spectrometer Probe (FSSP-100, Dye and Baumgardner, 1984, Gayet et al., 2007), the Cloud Particle Imager (CPI, Lawson et al., 1998) and the Polar Nephelometer (PN, Gayet et al., 1997). The systems provided measurements of particle number concentration, particle extinction coefficient, ice and liquid water content, effective diameter of the particles, particle phase function, and asymmetry parameter. The FSSP is sensitive to the typical size of liquid water droplets up to $45 \mu \mathrm{m}$. The CPI covers the particle sizes between $23 \mu \mathrm{m}$ and $2300 \mu \mathrm{m}$ with a resolution of $23 \mu \mathrm{m}$. The PN is sensitive to cloud particles in the size range of about $3 \mu \mathrm{m}$ to $800 \mu \mathrm{m}$. It measures an ensemble of both liquid and ice particles. The retrieval of PN data is described by Oshchepkov (2000) and Jourdan (2003). From PN data, the particle asymmetry parameter $g$ is determined, with $\theta$ being the scattering angle and $P$ the phase function:

$g=<\cos \theta>=\frac{1}{2} \int_{-1}^{1} \cos \theta \cdot P(\cos \theta) \cdot d \cos \theta$

It is used to discriminate between nonspherical (ice crystals, $g<0.82$ ) and spherical (liquid water droplets, $g>0.82$ ) particles (Gayet et al., 2002).

\subsubsection{SMART-Albedometer}

The Spectral Modular Airborne Radiation measurement sysTem (SMART-Albedometer) operated by the University of Mainz measures downwelling spectral irradiance $F_{\lambda}^{\downarrow}$ and upwelling nadir radiance $L_{\lambda}^{\uparrow}$ in the visible (350-1000 nm) and near-infrared range $(1000-2100 \mathrm{~nm})$. It is actively horizontally stabilized for airborne applications (Wendisch et al., 2001). A detailed description of the SMART-Albedometer configuration during ASTAR 2007 is presented by Ehrlich et al. (2008). From the measurements, the spectral cloud top reflectivity

$R_{\lambda}=\pi \mathrm{sr} \cdot L_{\lambda}^{\uparrow} / F_{\lambda}^{\downarrow}$

is determined. Further, the spectral slope ice index $I_{S}$ as introduced by Ehrlich et al. (2008) was analyzed in order to distinguish the cloud phase. It is defined by

$I_{S}=100 \cdot \frac{\Delta \lambda}{R_{1640 \mathrm{~nm}}} \cdot\left[\frac{d R}{d \lambda}\right]_{[1550 \mathrm{~nm}, 1700 \mathrm{~nm}]}$,

with $\Delta \lambda=(1700-1550) \mathrm{nm}$. Values below 20 indicate liquid water clouds.

Additionally, the cloud optical thickness is estimated by the method presented by Nakajima and King (1990) for liquid water clouds. The accuracy of the cloud optical thickness derived from the uncertainties of the measurements decreases with increasing optical thickness. The error is below $20 \%$ for clouds with an optical thickness of less than 20 .

\section{Cloud observations}

An overview of the cloud occurrence at different altitudes is provided in Sect. 3.1. The following four specific case studies are presented and their particular properties are discussed in the context of the atmospheric situation in Sects. 3.2 to 3.5:

A) optically thin layer of small spherical particles at low temperatures observed after the dissolution of a cloud with the ground-based Raman lidar at an altitude of $2 \mathrm{~km}$.

B) boundary layer mixed-phase cloud at an air mass intersection observed by airborne lidar in nadir configuration.

C) ice cloud in the free troposphere consisting of several ice layers observed with the ground-based Raman lidar.

D) cloud with double-layer structure and mixed-phase conditions in the free troposphere probed by airborne lidar in zenith configuration. 


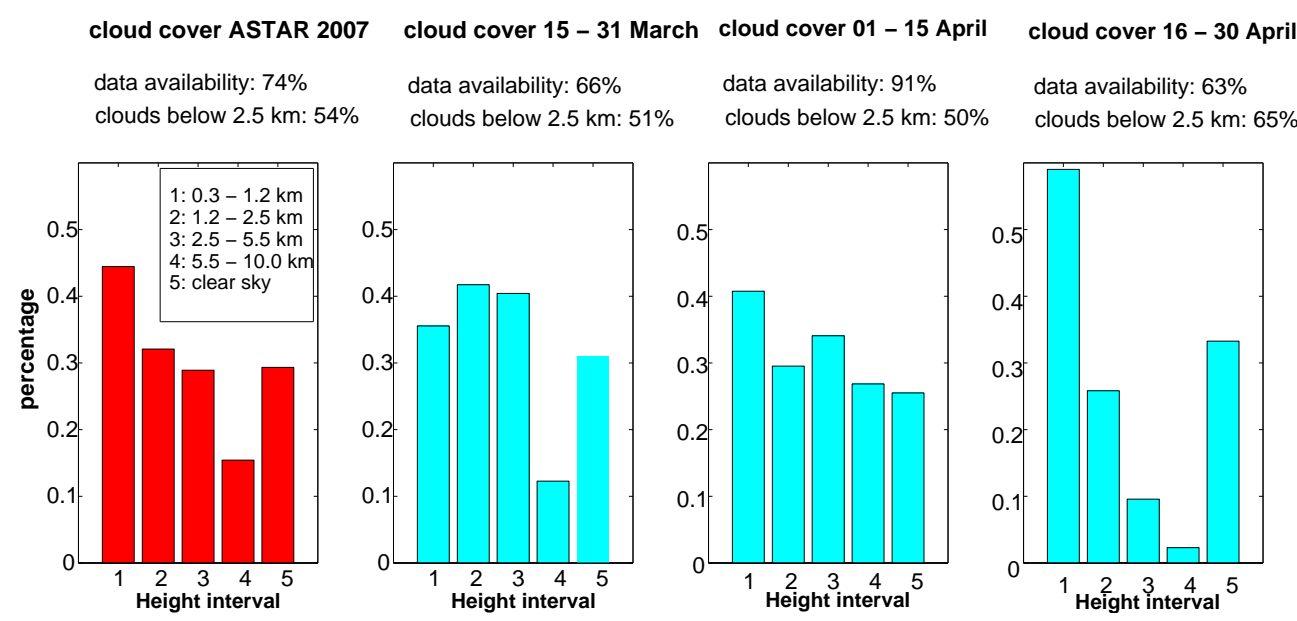

Fig. 1. Percentage of cloud cover at different height intervals for the whole time period, and divided into periods of 2 weeks. The height intervals refer to (1) $0.3-1.2 \mathrm{~km}$, (2) $1.2-2.5 \mathrm{~km}$, (3) $2.5-5.5 \mathrm{~km}$, (4) $5.5-10 \mathrm{~km}$ and (5) clear sky. The percentages refer to the respective time periods with a snow free window. Note that clouds in more than one height interval can be observed simultaneously, thus the percentage values do not add to give unity.

\subsection{MPL statistics of clouds during ASTAR 2007}

Generally, the cloud cover in the Arctic increases with the progression of spring to summer. The thawing of sea ice and the increased solar radiation and temperature in spring lead to more water vapor in the atmosphere available for cloud formation. During the transition period, a strong increase in low-level cloud cover is observed (Key et al., 2004). Cloud cover varies substantially from year to year. This has a high impact on the radiation budget, and a significant decrease of cloud cover might even be partly responsible for enhanced melting of sea ice (e.g. Kay et al., 2008). The analysis of the evolution of clouds during the spring transition period was one major aim of the ASTAR 2007 campaign.

For continuous cloud observations we used the MPL lidar system. The data processing is as described in Sect. 2.1. The main finding for the period of 15 March to 30 April 2007 is an increase of boundary layer and low level clouds through the analyzed time period from $51 \%$ to $65 \%$ (Fig. 1). The occurrence of clouds below $1200 \mathrm{~m}$ even increased from about $36 \%$ in the second half of March to 59\% in the second half of April, while the clear sky fraction remained roughly constant at about $25 \%$ to $33 \%$.

Our Ny-Ålesund results of increasing cloud cover for spring 2007 are similar to the MPL observations of Shiobara et al. (2003) for March and April 2002. Furthermore, ceilometer measurements in Ny-Ålesund documented an increase of low level cloud cover (0-2 km) from 30\% in March to 50\% in April 2001 (Kupfer et al., 2006). The cloud statistics presented here indicate that the atmospheric conditions of a typical Arctic spring were present in 2007.

This is of special interest as contrary to other years, the Arctic haze phenomenon with enhanced tropospheric aerosol load was not pronounced during the ASTAR 2007 time pe-

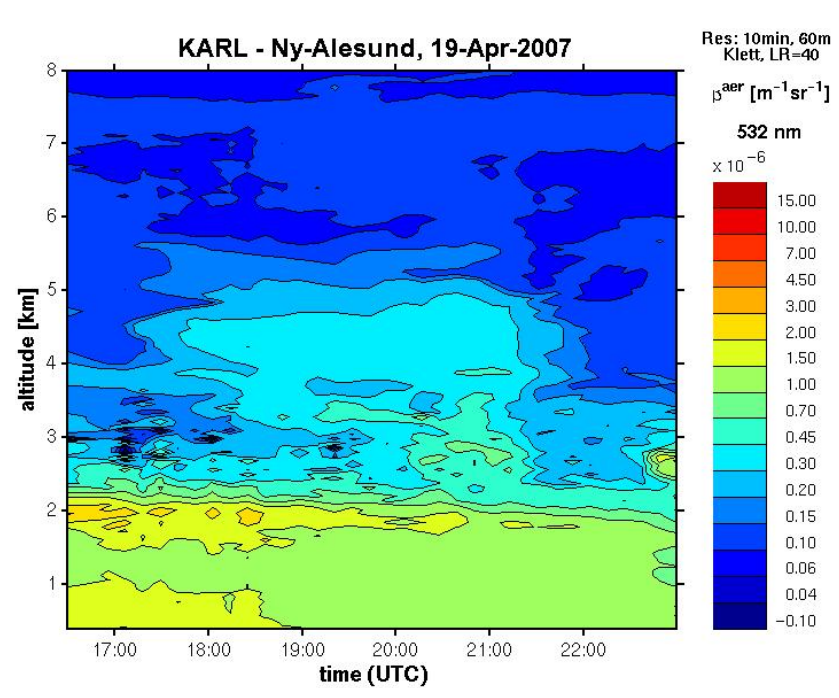

Fig. 2a. Time series of the particle backscatter coefficient in $\mathrm{Ny}$ Ålesund on 19 April 2007. The layer of spherical particles (case A) is visible at $2 \mathrm{~km}$ altitude.

riod (see Hoffmann et al., 2009). Arctic haze, observed regularly at Ny-Ålesund by sun photometer (Herber et al., 2002) and lidar (Ritter et al., 2004) in spring time, occurs often at altitudes below $3 \mathrm{~km}$ (Scheuer et al., 2003) and provides cloud condensation nuclei for cloud formation. However, even under clean conditions, particles in the accumulation mode are found in Svalbard throughout fall to spring (e.g. Ström et al., 2003). They are subject to long-range transport and remain sometimes for months in the Arctic atmosphere (Ström et al., 2003). Also sea salt particles of local origin serve as cloud condensation nuclei. The following case studies observed by lidar measurements during ASTAR 


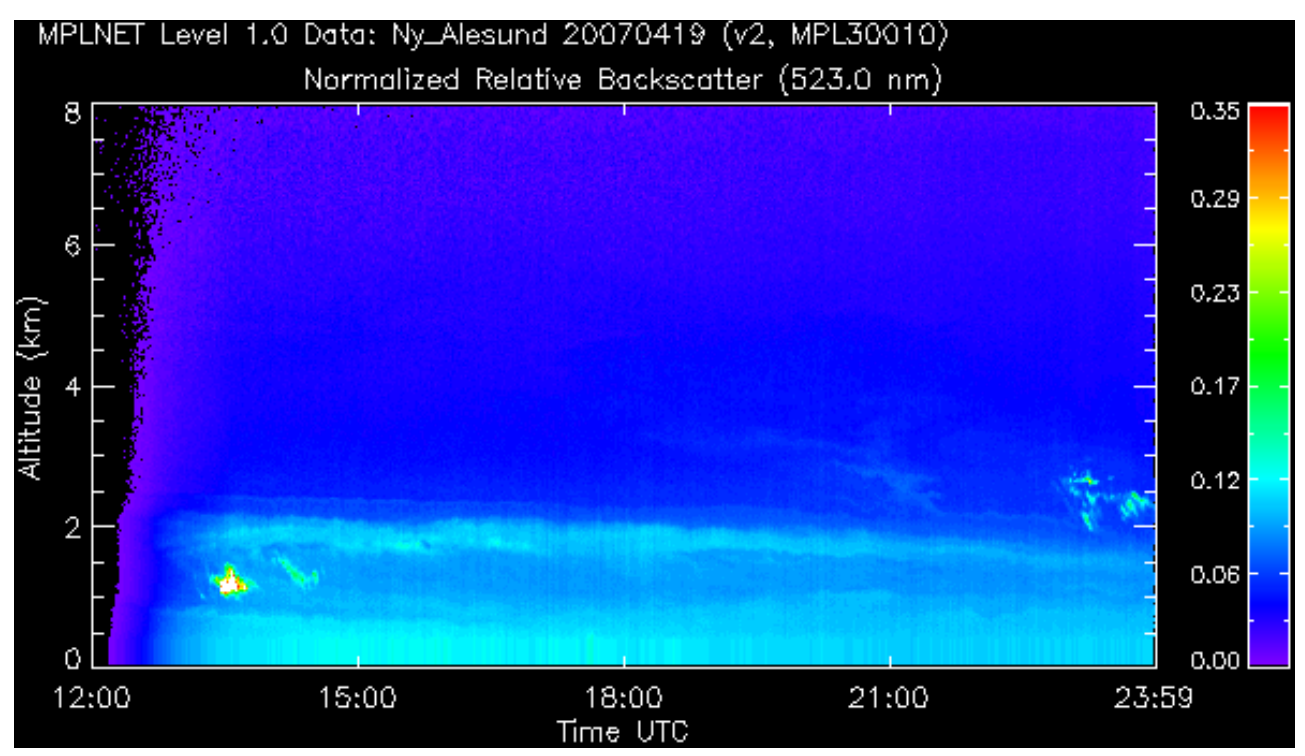

Fig. 2b. Time series of the MPL backscatter in Ny-Ålesund on 19 April 2007. The layer of spherical particles at $2 \mathrm{~km}$ altitude (case A) slowly dissolves.

2007 thus describe particular clouds which formed under relatively clean ambient conditions in the Arctic.

\subsection{KARL observation of a layer of spherical particles in the boundary layer (case A)}

The ground-based Raman lidar KARL observed a structure of enhanced backscatter in Ny-Ålesund over a 6 hour period during local afternoon / evening on 19 April 2007. The data processing is described in Sect. 2.2. Figure 2a shows an overview of the particle backscatter coefficient up to the tropopause level. In the lidar data, a persistent optically subvisible cloud at $7.5 \mathrm{~km}$ altitude and another one around $5 \mathrm{~km}$ altitude between 18 and 21:00 UTC were observed. However, in this study, the layer of enhanced backscatter and very low depolarization around $2 \mathrm{~km}$ altitude is discussed in detail (case A). Meteorological observations at the site recorded some snowfall in the morning from a persistent cloud at $2 \mathrm{~km}$ altitude from the top of the boundary layer. After noon the former cloud layer slowly dissolved and sank down as seen from the MPL lidar in Fig. 2b. Before 12:00 UTC snow on the exit window hindered MPL observations. During the KARL measurements, spherical, sub-micron particles were found in the altitude of this dissolving cloud.

Figure 3 (upper panel) shows the profiles of backscatter and depolarization ratio in the height interval including the layer of interest at 16:55 UTC. The volume depolarization was very close to the background value of $1.4 \%$ (typical for molecules of the air) within the layer and only increased slightly to $1.9 \%$ at $2 \mathrm{~km}$ altitude, right above the layer. Hence, apart from a shallow layer on top, the particles of case A are spherical in shape (for a review of polarization signals in lidar see Sassen, 1991). A radiosonde, launched in Ny-Ålesund at around 11:00 UTC, revealed high values of relative humidity ( $>90 \%$ ) in this layer between $1.8 \mathrm{~km}$ and $2.5 \mathrm{~km}$ altitude. Further, the sonde showed a low temperature of $244 \mathrm{~K}\left(-29^{\circ} \mathrm{C}\right)$ at $2 \mathrm{~km}$ and a weak inversion of $1.5 \mathrm{~K}$ with a minimal temperature of $241 \mathrm{~K}\left(-32^{\circ} \mathrm{C}\right)$ at $2.5 \mathrm{~km}$ altitude (Fig. 3, lower panel).

With the density profile of the radiosonde, the extinction and backscatter coefficient were derived in 10 min temporal and $60 \mathrm{~m}$ vertical resolutions (Ansmann et al., 1992). The optical depths of case A were determined to be 0.0633 for $355 \mathrm{~nm}$ and 0.0348 for $532 \mathrm{~nm}$ at $16: 55$ UTC. Hence, the layer was almost subvisible according to the definition of Sassen et al. (1989). For this time, an average lidar ratio $(\mathrm{LR})$ of $26.2( \pm 3) \mathrm{sr}$ for $355 \mathrm{~nm}$ and $20.2( \pm 6) \mathrm{sr}$ for $532 \mathrm{~nm}$ was derived for the whole layer. As the layer situated at an altitude of around $2 \mathrm{~km}$ slowly dissolved after 19:00 UTC (Figs. 2a and b), the LR increased slightly in both wavelengths (not shown). For a fixed chemical composition, a higher LR for spherical particles is related to smaller diameters (van de Hulst, 1981). As mentioned above, the low depolarization values of case A demonstrate that the backscattering particles were almost spherical. This is an indication of the presence of e.g. hydrated aerosol. In contrast, all Arctic haze events over Spitsbergen observed by KARL since 2000 showed a depolarization between $2 \%$ and $5 \%$ (Hoffmann et al., 2009), which is still low compared to aerosol events of desert dust (Sassen, 2008).

As the sphericity of the particles is evidenced by the depolarization measurements, the scattering properties can be described by Mie theory. The backscatter and extinction coefficients decrease with wavelength, which suggests that the 


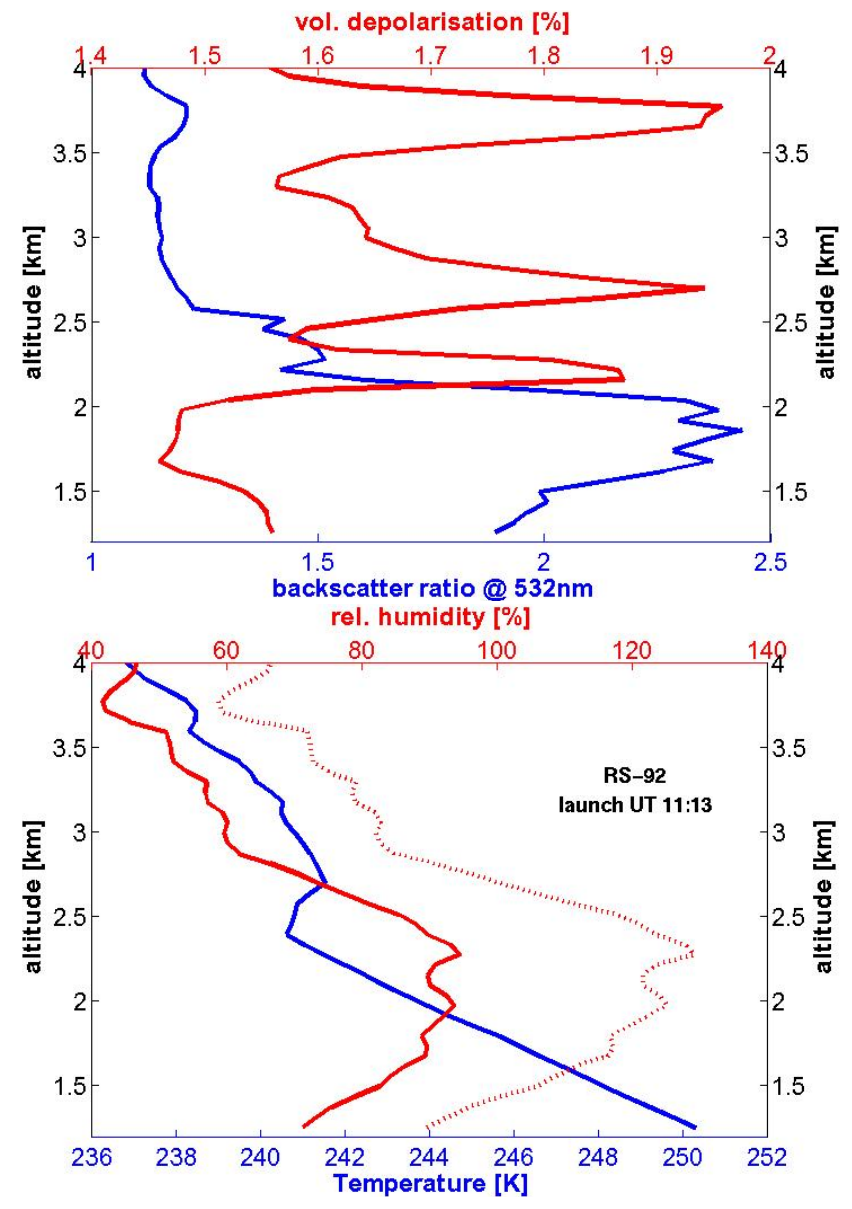

Fig. 3. Upper panel: Profiles of backscatter ratio (dimensionless, blue) and depolarization ratio (\%, red) for the height interval of the layer of small spherical particles (1.5-2 km, case A) observed on 19 April 2007 at 16:55 UTC. The vertical resolution is $60 \mathrm{~m}$, the temporal resolution $10 \mathrm{~min}$. Lower panel: Profiles of temperature (K, blue) and relative humidity (\%, red) measured by the radiosonde launched in Ny-Ålesund on 19 April 2007, 11:13 UTC. The dashed red curve denotes the relative humidity with respect to ice.

scattering particles were predominantly of sub-micron size, thus typical of aerosol and not cloud droplets. An inversion of the lidar data (backscatter coefficients at 3 wavelengths and extinction coefficients at 2 wavelengths, Böckmann, 2001) to derive the microphysical properties was performed. We used the inversion code originally developed by Kirsche and Böckmann (2006) for aerosol size retrieval from lidar data. It seeks the volume distribution function of spherical scatterers of size smaller than $1.25 \mu \mathrm{m}$ which matches to the lidar extinction and backscatter coefficients in an optimal way. A validation of the inversion technique can be found in Wandinger et al. (2002). It must be stated here that it is possible that particles larger than $1.25 \mu \mathrm{m}$ may exist as well. As the scattering properties of particles which are much larger than the lidar wavelengths are independent of wavelength, no

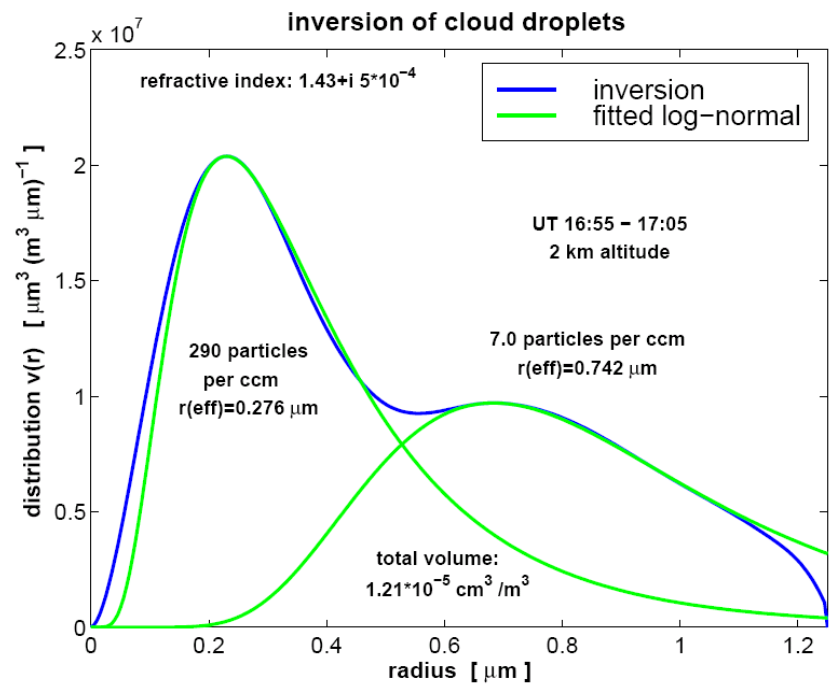

Fig. 4. Microphysical parameters of the layer of small spherical particles (case A) on 19 April 2007 at 16:55 UTC, derived from lidar data inversion. The blue curve represents the results of the inversion, the green curves show two log-normal size distributions fitted to the inversion curve.

information on their size distribution can be obtained. However, in case A, the backscatter and extinction coefficients are clearly decreasing with wavelength indicating that the majority of the particles were smaller than $1.25 \mu \mathrm{m}$.

The results of the inversion are presented in Fig. 4, showing the volume distribution function dependence upon the particle radius. The inverted volume distribution function (Fig. 4, blue curve) can be fitted by a bimodal lognormal size distribution (green curves). The parameters of the size distribution allow to retrieve the properties of the scattering particles which represent best the lidar data. Two modes of particle sizes can clearly be distinguished, the smaller one with an effective radius of around $280 \mathrm{~nm}$ and high particle number concentration $\left(290 \mathrm{~cm}^{-3}\right)$, and the larger one with an effective radius of around $740 \mathrm{~nm}$ and low particle number concentration $\left(7 \mathrm{~cm}^{-3}\right)$. Here the error in the effective radius is about $\pm 10 \%$, the error in the particle number concentration is $\pm 30 \%$. These particle size ranges are typical of aerosol in the accumulation mode. However, the size distribution of small water droplets can also include particles in the sub-micron range (e.g. Tomasi and Tampieri, 1976). Usually, Arctic cloud droplets have a larger effective radius in the range of $10 \mu \mathrm{m}$ for temperatures around $-20^{\circ} \mathrm{C}$ (e.g. Gayet et al., 2009).

The index of refraction was retrieved as $1.43+5 \times 10^{-4}$ i. The determination of a precise index of refraction from lidar data is challenging (Kirsche, 2008) as no direct information on absorption is available, which determines the imaginary part. However, a considerably low real part value, only slightly higher than that for pure water droplets $(1.33$, 
d'Almeida et al., 1991) was found. Both the real and the imaginary part of the index of refraction are significantly lower than the values derived for Arctic haze events with the same instrumentation (exceeding 1.5, Hoffmann et al., 2009). The index of refraction is in agreement with the value for sulfate aerosol (d'Almeida et al., 1991) or particles surrounded by a water shell. The effective radii of the bimodal log-normal size distribution as well as the total particle volume were found to be almost insensitive to changes in the real part of the refractive index. However, there is a dependence on the imaginary part of the refractive index: if it is artificially set to a larger value of $2 \times 10^{-3}$, which is the maximum value that corroborates with our calculations in the inversion code for typical aerosol, the mode of large particles around $0.77 \mu \mathrm{m}$ becomes the dominant one.

Under the (hypothetical) assumption that all of the scattering particles only consisted of pure water, a total liquid water amount of $1.21 \times 10^{-5} \mathrm{~g} \mathrm{~m}^{-3}$ in the thickest part of the cloud was derived (the total particle volume can be retrieved to a precision of $10 \%$ ). Later, at 21:12 UTC, the higher lidar ratio is translated as a decrease in the larger droplet size modus. Using the pressure and relative humidity from the radiosonde several hours earlier, a maximum water vapor content of $0.66 \mathrm{~g} \mathrm{~m}^{-3}$ was observed around $2 \mathrm{~km}$ altitude. This implies that even considering a pronounced temporal change of the water vapor content due to dissolution of the cloud, the vast majority of the water must be confined in the gas phase.

To further determine the origin of the layer, HYbrid Single-Particle Lagrangian Integrated Trajectories (HYSPLIT, Draxler and Hess, 1998) were applied to ECMWF analyses. Backward trajectories arriving at 17:00 UTC over the AWIPEV base were analyzed to interpret the inversion of the lidar data and obtain information on the possibility of pollution (not shown). The temperature and the relative humidity obtained from HYSPLIT analyses in the cloud layer at 17:00 UTC were similar to the values observed by the Vaisala RS-92 sonde at 11:13 UTC. HYSPLIT analyses suggest that the probed air masses came from the boundary layer of the Siberian coast and travelled 6 days via the Arctic to Svalbard. Only a small amount of precipitation $(<1 \mathrm{~mm})$, which can be a sink of aerosol, was given by the HYSPLIT model. Hence, a contamination with aerosol from the open sea or Eurasia cannot be ruled out.

However, generally during the ASTAR 2007 campaign, clean air was recorded by sun photometer and lidar measurements in Ny-Ålesund during the whole month of April (Hoffmann et al., 2009). For this specific day aerosol and trace gas samplers at the Zeppelin station, close by at $474 \mathrm{~m}$ altitude, showed clear conditions in the boundary layer (http://tarantula.nilu.no/projects/ccc/ sitedescriptions/no/index.html). For example, the $\mathrm{SO}_{4}$ concentration was only $0.25 \mu \mathrm{g} \mathrm{m}^{-3}$ and the $\mathrm{Cl} / \mathrm{Na}$ ratio was 1.43 , close to the value for sea water according to Shaw (1991). Therefore, the low index of refraction obtained by the lidar data inversion was most likely caused by spherical particles containing mostly water and some dissolved sulfate of maritime origin. Sulfate grows significantly in humid environments (Fitzgerald, 1975). For example if it were an $\left(\mathrm{NH}_{4}\right)_{2} \mathrm{SO}_{4}$ aerosol, a wet radius of $280 \mathrm{~nm}$ at about $84 \%$ $\mathrm{RH}$ would roughly correspond to a dry radius of $70 \mathrm{~nm}$. So in this maybe extreme example the particle consisted almost entirely of water.

Contrary to the findings presented here, Arctic haze events normally have an enhanced volume depolarization (Ishii et al., 1999), show a higher index of refraction (d'Almeida et al., 1991) due to an absorbing component as soot (Yamanouchi et al., 2005), show only a mono-modal log-normal distribution (Ström et al., 2003) and flow in drier air (Ishii et al., 1999). During the observation period, some of the bigger mode particles disappeared, as indicated by the increasing LR and decreasing backscatter, which is in agreement with a slow dissolution of this layer. Hence, our findings demonstrate a dissolving layer of spherical sub-micron particles at low temperatures around $241 \mathrm{~K}\left(-32^{\circ} \mathrm{C}\right)$, probably a dissolution of hydrated aerosol that was activated earlier in the cloud.

\subsection{AMALi observation of mixed-phase boundary layer clouds at an air mass intersection (case B)}

Airborne observations of mixed-phase boundary layer clouds were conducted on 9 April 2007. The flight path was synchronized with the Cloud-Aerosol Lidar and Infrared Pathfinder Satellite Observations (CALIPSO) track above the open Greenland Sea (Gayet et al., 2009). Lidar measurements were performed during the first part of the flight along a track from the west coast of Svalbard towards North-West direction at an altitude of $2760 \mathrm{~m}$ from 08:36 to 09:25 UTC (case B). Albedometer measurements were performed synchronously with the lidar observations, while in situ measurements were performed on the way back from 09:50 to 10:44 UTC at a flight altitude between $200 \mathrm{~m}$ and $1600 \mathrm{~m}$ during ascents and descents in the clouds. They are described in detail by Gayet et al. (2009). The CALIPSO overflight took place at 10:06 UTC. The meteorological situation, analyzed in detail by Richter et al. (2008) and Gayet et al. (2009), revealed the existence of two different air masses. Convective cloud rolls and northerly flow with low temperatures were observed in the southern part of the flight track, and warmer air advected from the South-West with scattered clouds in the northern part of the flight track.

Figure 5 shows the time series of lidar backscatter profiles. The two different air masses can clearly be distinguished. During the first part of the lidar flight (08:40-08:57 UTC), a continuous cloud deck with high backscattering ratio values (exceeding 50) was observed. The cloud top was rising with increasing boundary layer height, as confirmed by ECMWF analyses (Richter et al., 2008). The ground return was visible through the clouds for most time steps. This evidences that the lidar penetrated the clouds, and therefore the 


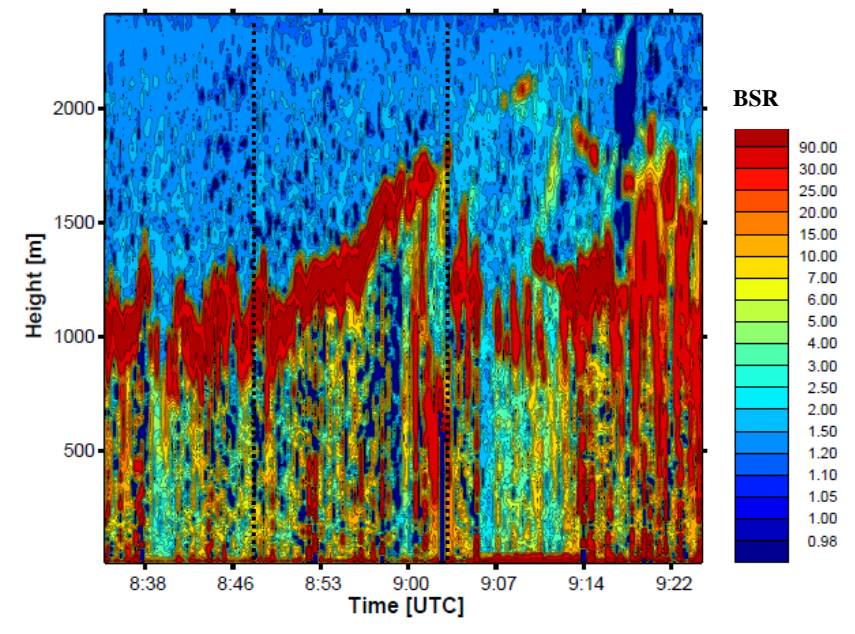

Fig. 5. Time series of airborne lidar backscatter profiles of case B (9 April 2007). Elevated values of the backscatter ratio below the cloud do not necessarily prove the existence of particles, they may be observation artifacts caused by the high extinction of the cloud. The dotted vertical lines indicate the profiles shown in Fig. 7.

vertical extent of the highly backscattering cloud layer dominated by liquid water droplets can also be derived. The mean geometrical thickness of the water dominated layer was estimated as $280( \pm 80) \mathrm{m}$ for the relatively homogeneous cloud. In the second part of the lidar flight, after 09:02 UTC, scattered clouds at different altitudes were present. Also in this part, the ground return of the lidar signal was mostly visible through the clouds (Fig. 5).

The time series of the depolarization ratio is presented in Fig. 6. In the clouds, the data exhibit predominantly values of around $10 \%$. This enhanced depolarization is caused by multiple scattering. However, in the mixing zone of the different air masses at around 09:02 UTC, the depolarization ratio was found to be significantly higher, up to $20 \%$. Exemplary individual profiles of the backscattering ratio and depolarization ratio for two times (08:48 and 09:03 UTC) are shown in Fig. 7. They exhibit different characteristics concerning the values and slopes of the profiles. A high backscattering ratio exceeding 30 and gradual increase of the depolarization up to $10 \%$ with cloud penetration depth was found for the time representative of the continuous cloud deck at 08:48 UTC. A much lower backscattering ratio of 15 and a higher value of the depolarization ratio of $20 \%$, enhanced immediately at the cloud top, were observed in the air mass mixing zone. This indicates a liquid water cloud top layer at 08:48 and an ice cloud at 09:03 UTC.

The temperature profiles obtained during the subsequent in situ measurements are shown in Fig. 8. During the northern part of the flight leg (blue color), the temperature was around $-12^{\circ} \mathrm{C}$ at the altitude of $550 \mathrm{~m}$, and $-21^{\circ} \mathrm{C}$ at $1500 \mathrm{~m}$. After 10:18 UTC, in the southern part of the flight (green color), the temperature below $1100 \mathrm{~m}$ was about $1.5 \mathrm{~K}$ colder. While

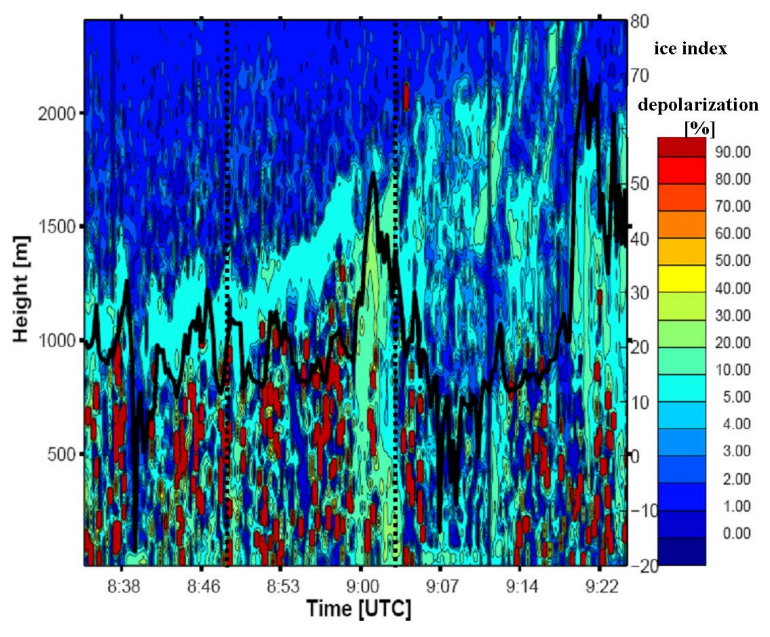

Fig. 6. Time series of airborne lidar depolarization (\%) of case B, 9 April 2007. The high depolarization values below the cloud are artifacts caused by the high extinction of the cloud. Superimposed in black and labeled at the right is a line plot of the ice index calculated from albedometer observations. An ice index exceeding 30 represents clouds consisting of ice crystals. The dotted vertical lines indicate the profiles shown in Fig. 7.

performing ascents and descents to probe the clouds with in situ instruments, the aircraft passed the air mass intersection. This is confirmed by the temperature profiles (Fig. 8). For the relatively homogeneous cloud layer in the southern part of the flight, a temperature inversion of $1 \mathrm{~K}$ was observed at $1100 \mathrm{~m}$ altitude. Such a temperature inversion directly above boundary layer clouds is a common feature in the Arctic (e.g. Curry et al., 1997).

In the following, a comparison of the lidar data with albedometer and in situ observations is given. Assuming pure water clouds, the maximum cloud optical thickness estimated from albedometer data shows values around 13-17 for the more homogeneous cloud deck in the South. In the mixing zone, the maximum optical thickness was lower (1113 assuming pure ice). Despite the high maximum optical thickness of the continuous cloud deck, the lidar penetrated the clouds for most time steps due to cloud inhomogeneities and the long integration time of $15 \mathrm{~s}$. For a shorter integration time of $1 \mathrm{~s}$, about every 15th lidar profile extended to the ground. This corresponds to "cloud gaps" with a distance of about $1 \mathrm{~km}$. Similar variability of marine stratocumulus clouds with a scale of $1-5 \mathrm{~km}$ was reported by Boers et al. (1988).

As the uppermost layer of a cloud has the highest influence on radiative transfer modeling (Ehrlich et al., 2009), it is crucial to determine the geometrical depth of this layer. The lidar results of the geometrical thickness are in agreement with the profiles of the asymmetry parameter $\mathrm{g}$, which are used to distinguish if a cloud consists mainly of liquid water droplets or ice crystals. For single profiles, the geometrical 

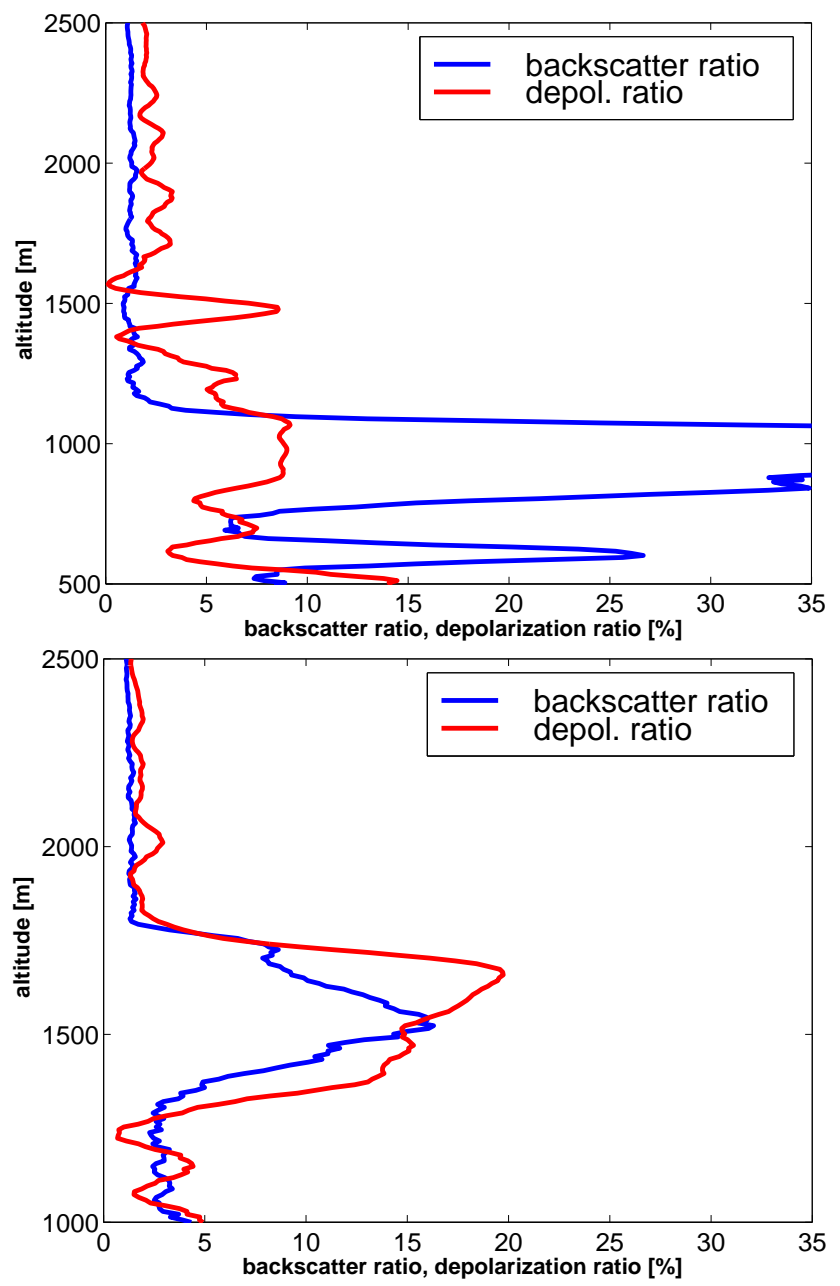

Fig. 7. Upper panel: Profiles of backscattering ratio (dimensionless, blue) and depolarization ratio (\%, red) of case B for a liquid-topped cloud at 08:48 UTC. The vertical resolution is $7.5 \mathrm{~m}$, the temporal resolution $15 \mathrm{~s}$. The lidar system was flying at around $3 \mathrm{~km}$ altitude pointing in nadir direction. The cloud top was located at $1100 \mathrm{~m}$ in the case of the liquid-topped cloud. Lower panel: Profiles of backscattering ratio (dimensionless, blue) and depolarization ratio (\%, red) of case B for an ice cloud at 09:03 UTC on 9 April 2007. The vertical resolution is $7.5 \mathrm{~m}$, the temporal resolution $15 \mathrm{~s}$. The lidar system was flying at around $3 \mathrm{~km}$ altitude pointing in nadir direction. The cloud top was located at $1800 \mathrm{~m}$ in the case of the ice cloud.

thickness of the liquid water dominated layer ranged from 100 to $700 \mathrm{~m}$. At the altitude between $800 \mathrm{~m}$ and $1500 \mathrm{~m}$, the in situ measurements detected mainly liquid water droplets (not shown, see Gayet et al., 2009). The FSSP showed a mean effective diameter of $20 \mu \mathrm{m}$ and a concentration of more than $50 \mathrm{~cm}^{-3}$. PN measurements revealed an extinction coefficient up to $35 \mathrm{~km}^{-1}$. Below the liquid dominated layer, ice crystals were observed. Here, the CPI showed ice effective diameters of up to $300 \mu \mathrm{m}$ and an ice particle concentration of more than $4001^{-1}$. The extinction coefficient

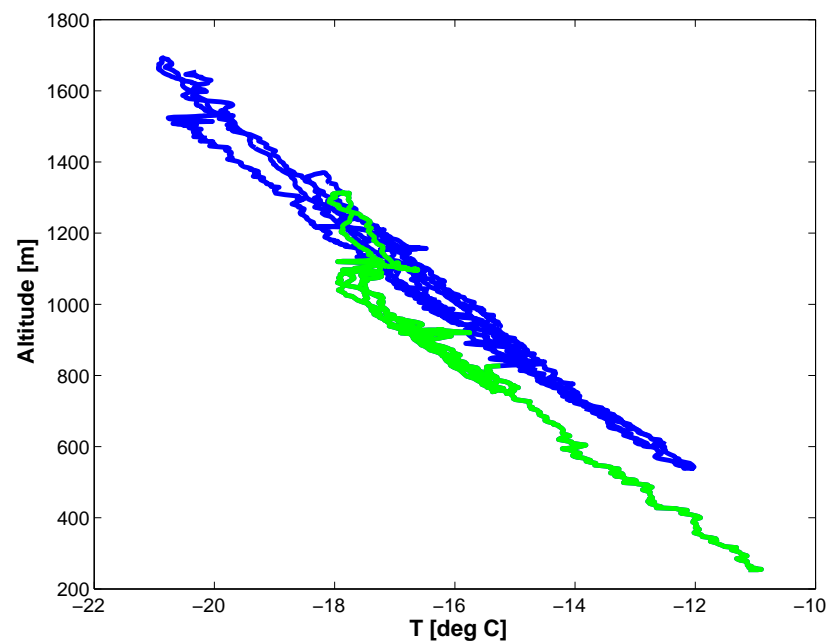

Fig. 8. Temperature profiles measured for case B (9 April 2007). Blue are the profiles measured in the North-Western part of the flight track, before 10:18 UTC, and green are the profiles measured in the South-Eastern part of the flight track, after 10:18 UTC.

was typically below $5 \mathrm{~km}^{-1}$. The values cannot be compared directly with the AMALi observations due to the time delay and advection. However, the spatial characteristics of the layer dominated by liquid water droplets observed by in situ measurements are in agreement with the vertical extent of the prevailingly liquid cloud layer from the airborne lidar measurements. With lidar, it was not possible to observe the ice crystals below the liquid dominated layer, as the laser return signal was attenuated.

The spectral slope ice index $I_{S}$ calculated from the cloud reflectance measurements (Ehrlich et al., 2008) is superposed as black line in the time series of depolarization (Fig. 6). Low values of 10 to 30 , indicating water or mixed-phase clouds with predominantly liquid contribution, are typical for most of the clouds observed. This is in agreement with the depolarization of about $10 \%$ recorded for cloud system $\mathrm{B}$. The depolarization values are typical for liquid water clouds in which multiple scattering occurs. This indication of a cloud top layer dominated by liquid water droplets is also consistent with the observations of glory from the aircraft (Rauber and Tokay, 1991; Ehrlich et al., 2009). In the air mass mixing zone, however, the ice index shows enhanced values up to 50 indicating clouds dominated by ice crystals. This confirms the lidar observation of enhanced depolarization values, characterizing a glaciated cloud.

The temporal stability and spatially limited occurrence of glaciated clouds within a mixed-phase cloud system was confirmed by subsequent in situ observations. About 15 minutes after the lidar and albedometer observations, at 10:18:30 UTC, the in situ measurements observed a cloud consisting of ice only. The asymmetry parameter obtained from the PN was below or equal to 0.82 for $15 \mathrm{~s}$ (horizontal extent of around $900 \mathrm{~m}$ ). The data correspond to a flight 


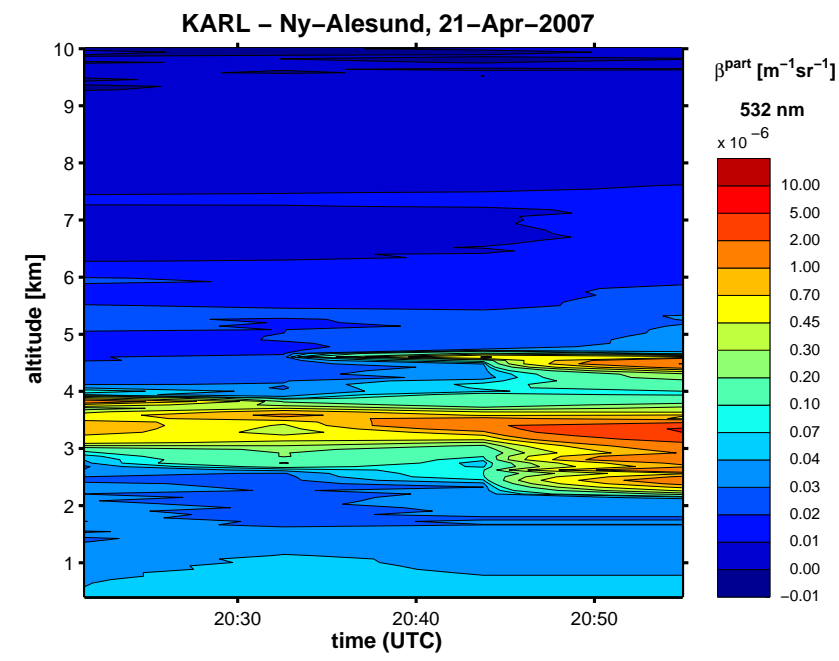

Fig. 9. Time series of the particle backscatter coefficient at NyÅlesund of case C (21 April 2007). Up to four different layers of enhanced backscatter coefficient are visible simultaneously between 2 and $5 \mathrm{~km}$ altitude.

altitude of about $900 \mathrm{~m}$ and were collected in the mixing zone of the air masses, also indicated by the transition of the temperature profiles (Fig. 8).

The presented lidar, albedometer and in situ measurements show a band of local glaciation within mixed-phase cloud systems caused by the mixing of two different air masses. According to Korolev and Isaac (2003), Shupe et al. (2008) and Korolev and Field (2008), the updraft of moist air masses is a necessary condition for constantly producing supercooled liquid droplets near the cloud top and maintaining the mixed-phase cloud despite the Bergeron-Wegener-Findeisen process. In the observations of case $\mathrm{B}$, the constant updraft of moist air above the warm open ocean was disturbed by the mixing of two air masses with different properties. The disturbance of the updraft and hence also the glaciation processes were confined to a small band of $1-2 \mathrm{~km}$ along the air mass mixing zone.

\subsection{KARL observation of a multiple layered midlevel ice cloud (case C)}

On 21 April 2007 an ice cloud containing up to four different layers was observed by ground-based lidar over Ny-Ålesund from 20:20 to 21:00 UTC (case C). Figure 9 shows the time series of the backscatter coefficient at $532 \mathrm{~nm}$ wavelength. The cloud layers in question are visible between 2.5 and $5 \mathrm{~km}$ altitude. Altogether, this cloud was optically thin, but much denser compared to the layer of small spherical particles presented in case A. At 20:30 UTC its optical depth amounted to 0.167 at $532 \mathrm{~nm}$ and 0.169 at $355 \mathrm{~nm}$. The corresponding LRs were $33( \pm 2)$ sr and $18( \pm 1)$ sr for the respective wavelengths. The cloud consisted purely of ice crystals which showed a very high volume depolarization of up to $70 \%$.
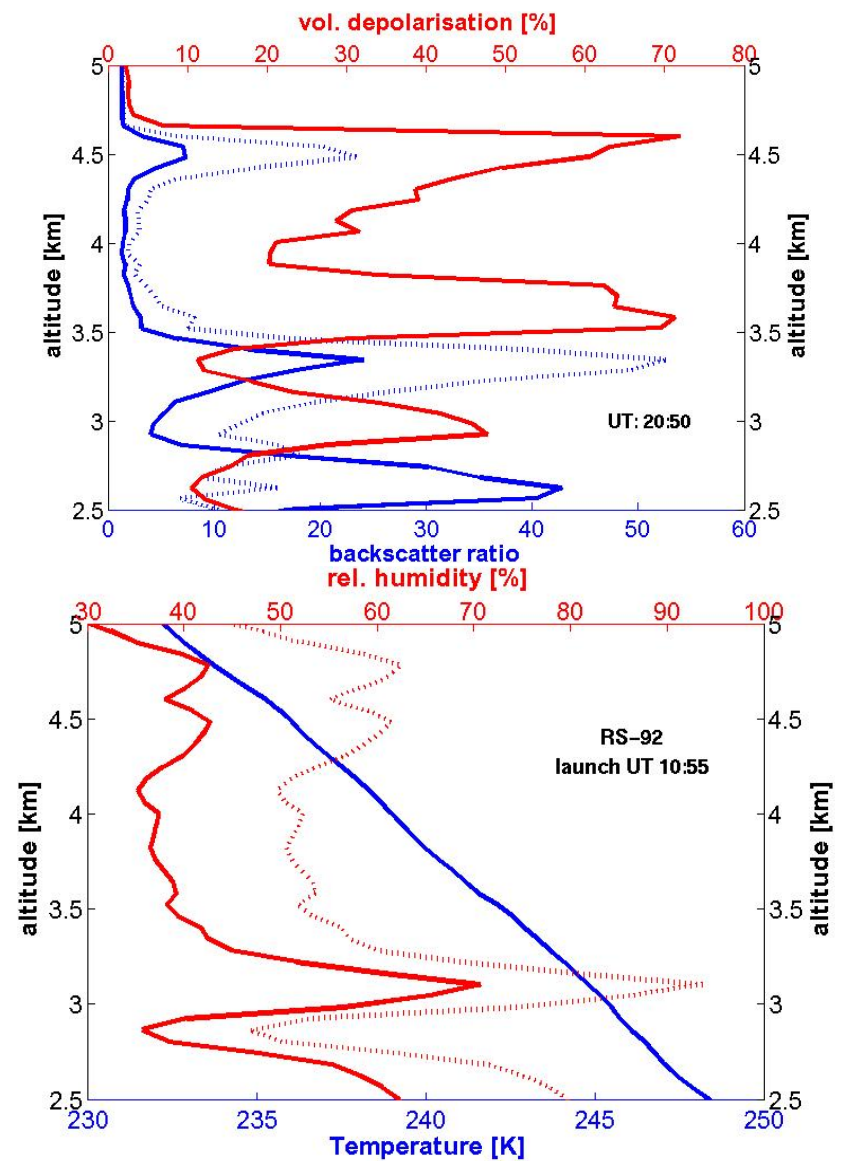

Fig. 10. Upper panel: Backscatter (dimensionless, blue) and depolarization $(\%$, red) profiles of the cloud observation of case C (21 April 2007) around 20:50 UTC. The dashed blue curve denotes the backscatter ratio at $532 \mathrm{~nm}$, the blue one to the backscatter ratio at $355 \mathrm{~nm}$. The vertical resolution is $60 \mathrm{~m}$, the temporal resolution 10 min. Lower panel: Temperature (K, blue) and relative humidity $(\%$, red) profiles of the radiosonde launched at 11:00 UTC on 21 April 2007. The dashed red curve denotes the relative humidity with respect to ice.

At 20:50 UTC the lidar profiles presented in Fig. 10 (lower panel) exhibited a distinctive internal structure of the cloud with three layers of enhanced backscatter coefficients. The highest layer at around $4.5 \mathrm{~km}$ showed almost the same particle backscatter of $3 \times 10^{-6} \mathrm{~m}^{-1} \mathrm{sr}^{-1}$ for both wavelengths, a value as expected for cirrus. Also the LRs for both wavelengths are similar: $19.8 \mathrm{sr}$ vs. $17.9 \mathrm{sr}$. This translates into an optical depth of 0.11 for both wavelengths. However, the subjacent layer between 3 and $3.5 \mathrm{~km}$ altitude was accompanied by a minimum of the depolarisation of only $10 \%$, and the backscatter was higher in the UV compared to the visible wavelengths. On the other hand, the cloud optical thickness detected in the two wavelengths was comparable $(0.25$ for $532 \mathrm{~nm}$ and to 0.21 for $355 \mathrm{~nm}$ ). This means that the LR for 
the UV ( $6.5 \mathrm{sr})$ is lower than the LR for $532 \mathrm{~nm}(14.4 \mathrm{sr})$. The lowermost cloud layer at around $2.6 \mathrm{~km}$ altitude, which was basically visible in the UV, is striking because it shows a different LR: $37.0( \pm 1)$ sr for the visible branch, but only 3.0 $( \pm 0.2)$ sr for the UV.

For case C, we analyze the optical properties of the cloud system and discuss deductions for the microphysics of the ice crystals. The cloud exhibits the lowest LR measured by KARL during the ASTAR 2007 campaign. Due to this extremely low LR in the UV, the optical depth of the cloud layer at $2.6 \mathrm{~km}$ is higher in the visible than in the UV $(0.312$ vs. 0.216). To substantiate this conclusion, the backscatter coefficient and backscatter ratio were additionally calculated with the Klett approach (Klett, 1985) applying the obtained LR. The results were found to be in agreement with the above data calculated with the method presented by Ansmann et al. (1992). Choosing a higher LR in the Klett method produces a physically unrealistic backscatter ratio smaller than 1 below the cloud base. Due to the non spherical shape of the ice cloud particles and their size, a lidar inversion code based on Mie theory cannot retrieve their microphysical properties.

Lidar observations of ice clouds have been performed by various groups. A typical LR value for cirrus clouds is around $30 \mathrm{sr}$ at $532 \mathrm{~nm}$ wavelength (Chen et al., 2002; Giannakaki et al., 2007). Our observations of the LR at $532 \mathrm{~nm}$ agree with these values in the given standard deviation. Reichardt et al. (2002) calculated LR and depolarization of (almost) hexagonal particles in random orientation with a ray tracing code. They found lidar ratios as low as $3 \mathrm{sr}$, albeit frequently in conjunction with very high depolarization. The values of lidar ratio and depolarization of case $\mathrm{C}$ seem to best match with plates of high aspect ratio (Reichardt et al., 2002, their Fig. 7).

As the LR is influenced by particle size, shape and aspect ratio of the ice crystals, it depends on the cloud temperature, which determines the formation of different ice crystal habits (Sassen and Comstock, 2001), as well as cooling rates and aerosol properties at ice supersaturation (Haag and Kärcher, 2004). However, simulated backward trajectories show that the air mass investigated here did not pass areas where the uptake of pollution was likely (not shown). The temperature and humidity profile of case $\mathrm{C}$ was estimated from radio sounding measurements several hours earlier (Fig. 10, lower panel). At around 11:00 UTC, the temperature decreased from $248 \mathrm{~K}\left(-25^{\circ} \mathrm{C}\right)$ at $2.5 \mathrm{~km}$ altitude to $234 \mathrm{~K}\left(-39^{\circ} \mathrm{C}\right)$ at $5 \mathrm{~km}$ altitude. However, the shown differences in the optical properties of the cloud, namely the different LR and the depolarization, are surprisingly large for the temperature range. Korolev et al. (2000) and Bailey and Hallett (2002) showed that irregular ice crystals dominate all temperature intervals of interest here. They observed a high fraction of irregular ice crystals $(>85 \%)$ in stratiform clouds and by cloud chamber experiments, respectively. The evidence shows that changes in the shape and size of the ice crystals of this cloud system are pronounced. The findings suggest that we observed a

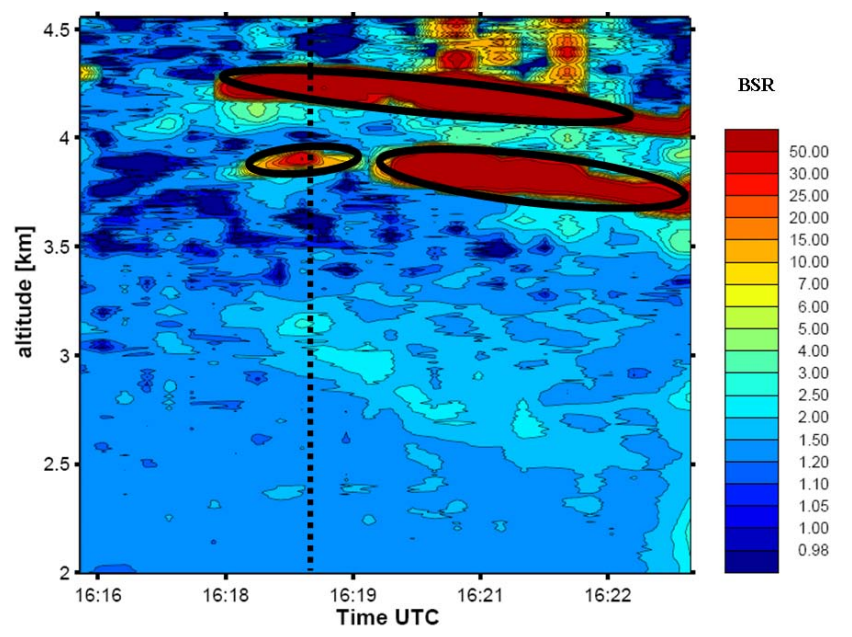

Fig. 11. Time series of the airborne backscattering ratio of case D (14 April 2007). Encircled in black are the cloud areas of high backscatter values. The aircraft was flying at $1300 \mathrm{~m}$ above ground with the lidar system pointing in zenith direction. The dotted vertical line corresponds to the time of the profile shown in Fig. 13.

cloud of highly unusual and inexplicable characteristics. It is worth identifying similar cloud cases by lidar, and studying the evolution of the ice particle size and shape in combination with in situ probing.

\subsection{AMALi observation of a two-layer midlevel cloud (case D)}

On 14 April 2007, the Polar-2 aircraft went from Longyearbyen towards the South along the West coast of Svalbard, in the direction of an approaching high pressure system. A two-layer cloud structure was observed by the zenith pointing AMALi (case D). The system had a horizontal extent of around $30 \mathrm{~km}$ (8 flight minutes from 16:18 to 16:26 UTC). As the aircraft was cruising at constant altitude of $1300 \mathrm{~m}$ until 16:24 UTC, only this first part of the lidar data is shown in the figures. The signal was smoothed vertically with a running mean over 10 data points, the applied time resolution was $15 \mathrm{~s}$. The signal to noise ratio at $4 \mathrm{~km}$ altitude was 15 . The temperature at $4 \mathrm{~km}$ altitude was estimated to be around $-25^{\circ} \mathrm{C}$ and the pressure was about $590 \mathrm{hPa}$ (radiosonde measurement in Ny-Ålesund at 11:00 UTC). Two separated, geometrically thin liquid cloud layers $(150 \mathrm{~m}$ vertical extent each) with high backscatter ratio and low depolarization were observed (Figs. 11 and 12). The upper cloud was centered at $4.2 \mathrm{~km}$ altitude, the lower cloud at $3.9 \mathrm{~km}$. In between, the enhanced depolarization and low backscatter signal revealed the existence of precipitating ice particles. A cirrus cloud was located above the two-layer cloud system with a slanted cloud base at around $5.5 \mathrm{~km}$ (not shown in Figs. 11 and 12), which prohibited the characterization of the double layer cloud by the radiation measurements. However, 


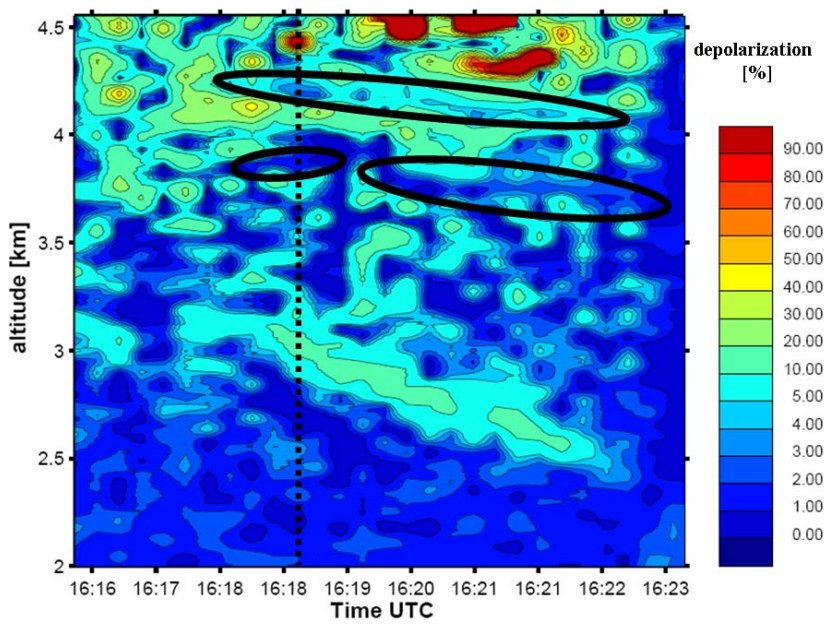

Fig. 12. Time series of the airborne depolarization ratio of case D (14 April 2007). Encircled in black are the same cloud areas as in Fig. 11. The aircraft was flying at $1300 \mathrm{~m}$ above ground with the lidar system pointing in zenith direction. The dotted vertical line corresponds to the time of the profile shown in Fig. 13.

the airborne lidar observations of the two-layer cloud showed that the backscatter ratio of the lower layer was smaller than that of the higher layer at the beginning of the cloud observation.

For the measurements of case D, the cloud phase of the double layer cloud was determined from the profiles of backscatter and depolarization ratio. In the time series of the backscatter ratio (Fig. 11), the areas of enhanced backscatter ratio are encircled in black. The depolarization values for these cloud parts are low (Fig. 12). The analysis of single profiles of backscatter and depolarization ratio (Fig. 13) provides further evidence of two geometrically thin liquid water clouds with an ice layer below each liquid cloud layer. The gradual increase of the depolarization signal in the highly backscattering height intervals is caused by multiple scattering, whereas the sharp increase of the depolarization signal in the layers below the liquid clouds is interpreted as the existence of depolarizing ice crystals.

As multiple scattering leads to an enhanced apparent optical depth (Nicolas et al., 1997), only a maximum value for the optical depth can be estimated as follows: The maximum backscatter coefficient of the upper liquid layer was around $10^{-4} \mathrm{~m}^{-1} \mathrm{sr}^{-1}$. Multiplication of this value with a typical cloud LR of 30 (e.g. Chen et al., 2002) and integration over the cloud altitude $(150 \mathrm{~m})$ leads to an estimation of the optical thickness in the order of 0.45 , which represents an optically thin cloud.

Now we consider possible formation mechanisms of the double-layer cloud of case D by analyzing the meteorological conditions. In contrast to multiple cloud layers in the Arctic boundary layer observed regularly in summer (e.g. Intrieri et al., 2002a; Luo et al., 2008), multiple layer clouds in the free troposphere are less frequently reported. A complex

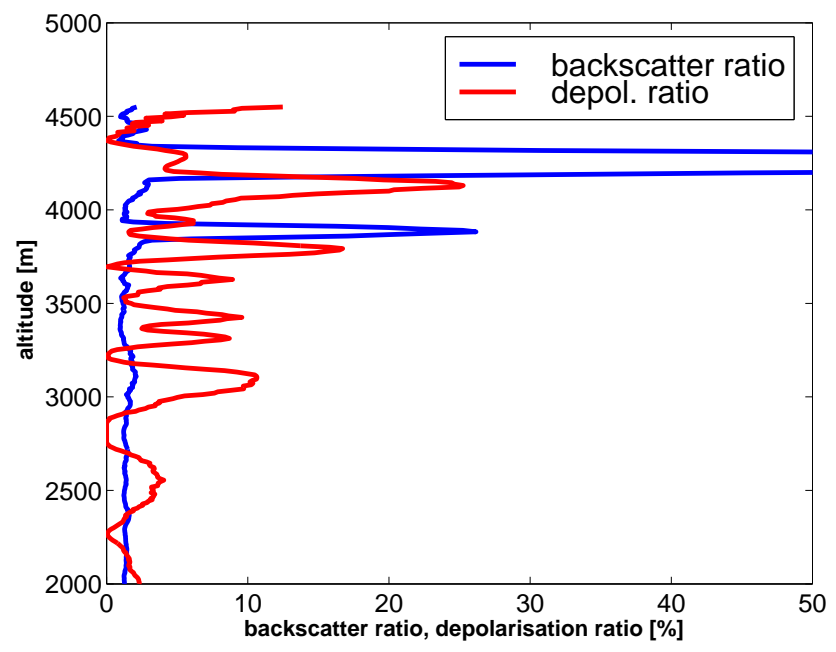

Fig. 13. Profiles of backscatter ratio (dimensionless, blue) and depolarization ratio (\%, red) of case D (14 April 2007) at 16:18:45 UTC. The vertical resolution is $7.5 \mathrm{~m}$, the temporal resolution $15 \mathrm{~s}$. The aircraft was flying at $1300 \mathrm{~m}$ above ground with the lidar system pointing in zenith direction. The liquid layers (high backscatter ratio, low depolarization) are located at 3900 and $4200 \mathrm{~m}$.

multiple layer cloud system with layers up to $5.5 \mathrm{~km}$ altitude was analyzed by Hobbs et al. (2001). They found ice crystals precipitating from the individual cloud layers into lower layers, and at times evaporating before reaching the ground.

Meteorological analyses of case D revealed that behind a trough propagating eastward, the low level wind turned from north-westerlies to easterlies in the period between 12:00 UTC and 18:00 UTC. However, the wind speed was rather low, with values around $2 \mathrm{~m} \mathrm{~s}^{-1}$ at $10 \mathrm{~m}$. Above the prevailing easterly winds near ground level, westerly winds dominated at higher levels above Spitsbergen (Fig. 14). Associated with the approaching ridge, warm and moist air was transported to the Svalbard area at the altitude of the cloud observation (Fig. 14a). As the wind at the aircraft's cruising altitude $(1325 \mathrm{~m})$ and the cloud altitude came from the West, the lidar observations were performed along a cross section perpendicular to the wind direction prevailing at cloud level. ECMWF analyses reveal the existence of an area of humid air masses (relative humidity around saturation) at $700 \mathrm{hPa}$ and enhanced relative humidity up to $90 \%$ at $500 \mathrm{hPa}$ (Fig. 14b and c). Midlevel clouds were analyzed in the observation area. However, the small scale structure of the observed cloud D could not be resolved by the ECMWF analyses.

Different mechanisms might be responsible for the lifting of the air masses and cloud formation: A possible scenario is that the humid air masses were lifted orographically. Until about 12:00 UTC, westerlies dominated in the lower troposphere and the flow perpendicular to the coast line passed the mountains of the Svalbard archipelago. However, the cloud was observed on the windward side and in the direct vicinity 

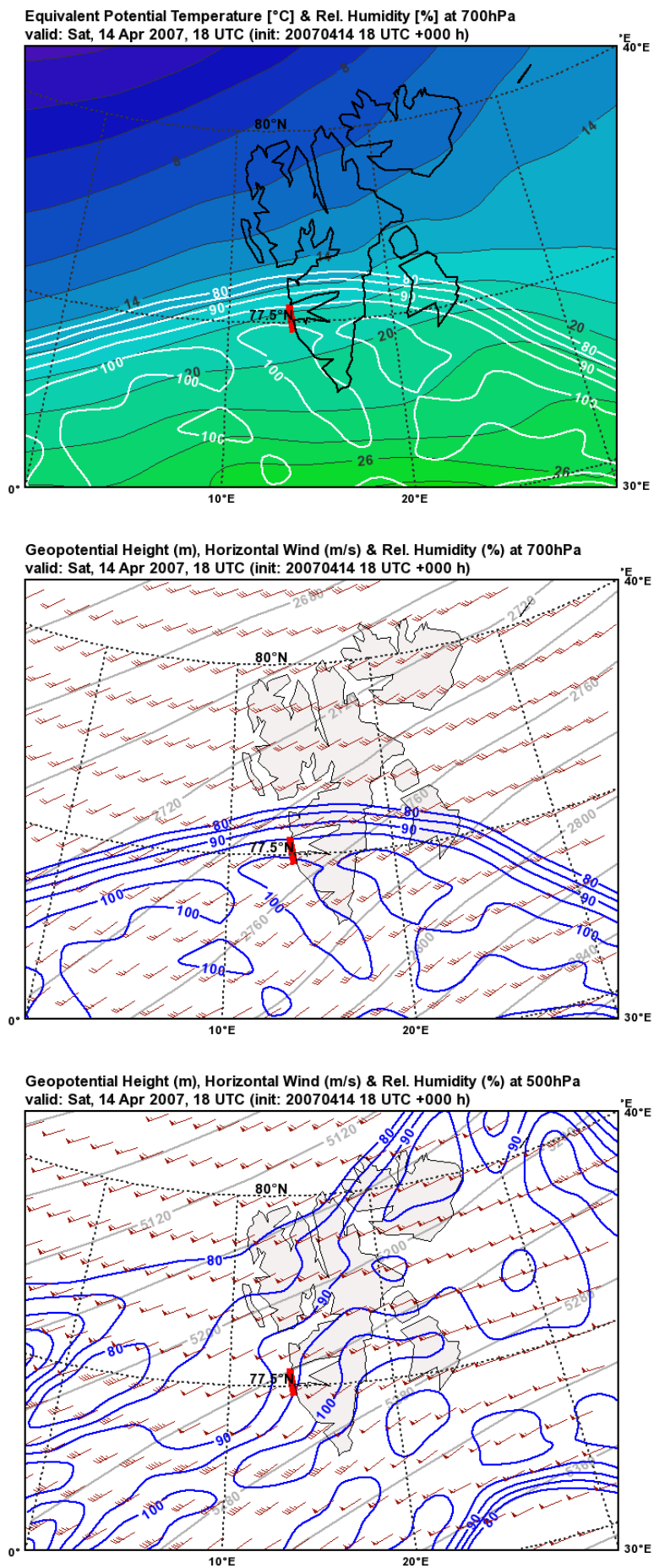

Fig. 14. (a) Operational ECMWF analyses of equivalent potential temperature (color shaded, ${ }^{\circ} \mathrm{C}$ ) and relative humidity with respect to water (white contour lines [\%]) at the $700 \mathrm{hPa}$ pressure level (b) geopotential height (gray contour lines [m]), relative humidity with respect to water (blue contour lines [\%]) and wind barbs $\left(\left[\mathrm{m} \mathrm{s}^{-1}\right]\right.$, short barbs equal to $2.5 \mathrm{~m} \mathrm{~s}^{-1}$, long to $5 \mathrm{~m} \mathrm{~s}^{-1}$ ) at the $700 \mathrm{hPa}$ pressure level (c) same parameters as (b) at the $500 \mathrm{hPa}$ pressure level valid at 14 April 2007 18:00 UTC (case D). The flight track is indicated as a red line. of Svalbard (less than $5 \mathrm{~km}$ off land). Therefore, the observed clouds cannot be typical lee wave clouds. Another possible explanation is that the flow above the Svalbard archipelago was interrupted by the change of the wind direction in the lowermost troposphere. As the forcing of gravity waves diminishes, an upstream shift of the waves might occur under these transient conditions (Chen et al., 2007). A third possibility is that cloud filaments formed due to the enhanced vertical and horizontal wind shears in the strongly divergent flow. Lifting by one of the mentioned mechanisms and subsequent cooling of the moist air is probably the cause of the formation of at least the upper liquid cloud layer. As precipitation between the individual cloud layers was observed, and the lower liquid cloud layer exhibits a lower optical thickness, the double-layer structure D might be the result of ice crystal precipitation which evaporated below the upper cloud (as proposed by Harrington et al., 1999). Radiative cooling or further orographic lifting led to cooling of the humid layer, resulting in the second cloud layer.

\section{Summary: Arctic clouds observed by lidar technique}

In this article, an overview of the cloud situation in $\mathrm{Ny}$ Ålesund (Svalbard) during March and April 2007 was presented. In this time period, the cloud cover of low level clouds (cloud top below $2.5 \mathrm{~km}$ ) increased from $51 \%$ to $65 \%$. The lidar data of four individual case studies (A-D) of noticeable clouds were analyzed in detail. They showed special properties of Arctic clouds and indicated links between cloud processes and the meteorological conditions.

The observations of case A revealed an optically thin layer of enhanced backscatter and very low depolarization at low temperatures $\left(-30^{\circ} \mathrm{C}\right)$ directly after a precipitating low level cloud. The inversion of the Raman lidar data provided an estimate of the particle size, which was bimodal in the accumulation mode. The lower particle radius of $280 \mathrm{~nm}$ is typical for the order of magnitude of Arctic aerosol. However, the optical properties suggest differences to the typical Arctic haze. As no strong events of Arctic haze were observed in this time period (Hoffmann et al., 2009) and only low concentrations of aerosol were recorded by in situ measurements on this day, we hypothesize that we observed hydrophilic aerosol of local origin (e.g. sulfate from sea spray) which was activated in a cloud and survived at least for several hours after the cloud dissolved. The observations of case $\mathrm{A}$, a layer consisting of sub-micron spherical particles at low temperatures $\left(-30^{\circ} \mathrm{C}\right)$, may be of importance for radiative transfer calculations and climate modeling, and are an interesting example of cloud and aerosol interaction even in a pristine environment. To our knowledge this is the first estimation of a size distribution of Arctic cloud activated aerosol derived from lidar data. In the future, the comparison of similar cases with in situ data is extremely important to obtain an 
improved picture of the microphysical properties of this kind of particles, their temporal evolution and radiative impact.

Case B describes a mixed-phase cloud system above the open ocean, which experiences a change in air masses. At the air mass intersection, the characteristic vertical structure of a liquid layer on top and an ice layer below was not observed. Instead, the whole cloud consisted of ice only, as evidenced by airborne lidar and confirmed by spectral radiation measurements. The glaciation process remained confined to a small cloud band of about $1-2 \mathrm{~km}$ horizontal extent, as was also shown by subsequent in situ measurements at the air mass intersection. Our results confirm that a major atmospheric disturbance such as a change in the air mass has a strong impact on the cloud thermodynamic phase. The air mass mixing prevents the continuous updraft of moist air parcels from the open ocean, which is a necessary condition for the equilibrium of mixed-phase clouds.

Case $\mathrm{C}$ represents an example of an ice cloud with a highly variable internal structure. The observation of ice cloud layers with very different optical properties seems a special case compared to the microphysical findings of Korolev et al. (2000) and Bailey and Hallett (2002), who describe prevailing irregular structures of ice crystals for a wide temperature range. A high backscatter peak for the $355 \mathrm{~nm}$ wavelength, resulting in a low LR was found. Our observations emphasize that even in a pristine Arctic environment without anthropogenic pollution, ice clouds cannot be considered as a homogeneous, simple phenomenon. This poses a challenge for the precise description of pure ice clouds in numerical simulations.

Case D describes the observation of a double-layer cloud at $4 \mathrm{~km}$ altitude. At a temperature of about $-25^{\circ} \mathrm{C}$, we recorded two geometrically and optically thin individual liquid cloud layers. Below each layer, ice precipitation was found. Multi-layer cloud systems consisting of geometrically thin liquid cloud layers are observed regularly in the Arctic boundary layer (Verlinde et al., 2007; Luo et al., 2008). The temperature inversion plays a key role for the formation processes (Curry et al., 1997). The analysis of the meteorological conditions for the observed double layer midlevel cloud suggests that the formation of the double layer structure was influenced by local orography, which induces lee waves and affects the wind field even in the free troposphere.

Little is known about the frequency of occurrence of subvisible clouds and their radiative impact in the Arctic. Additionally to the two cases provided in this article (case $\mathrm{C}$ and D), other examples of optically thin Arctic clouds observed by lidar technique were presented by Lampert et al. (2009) and Hoffmann et al. (2009). The study of Wyser and Jones (2005) suggests the frequent existence of optically thin clouds in winter, as the monthly mean cloud cover during SHEBA observed by lidar/radar instruments, which are also sensitive to optically thin and subvisible clouds, exceeded $60 \%$. In contrast, the satellite based cloud retrieval showed values of only 50\% (Wyser et al., 2005). This leads to difficulties of cloud representation in models (Wyser et al., 2008).

As part of ongoing work, we plan to undertake mesoscale numerical simulations of the optically thin clouds in order to gain a deeper understanding of the factors contributing to the formation of such particular clouds. For future campaigns, we recommend that the formation process and life time of optically thin clouds and haze layers be analyzed and that the lidar observations be compared with the microphysics data obtained from in situ instruments.

Acknowledgements. We would like to thank the DLR flight crew and the OPTIMARE GmbH for their support with the airborne measurements, and the AWIPEV base personnel for the measurements and attendance of the instruments in Ny-Ålesund. The MPLNET project is funded by the NASA Earth Observing System and Atmospheric Radiation Sciences Program. Wenche Aas from NILU provided the in situ measurements from the Zeppelin station at http://tarantula.nilu.no/projects/ccc/sitedescriptions/no/index.html. Further, we would like to thank Robyn Schofield for improving the English quality. The two anonymous referees are gratefully acknowledged for their suggestions to clarify the content and structure of the manuscript.

Edited by: T. Garrett

\section{References}

d'Almeida, G. A., Koepke, P., and Shettle, E. P. (eds.): Atmospheric Aerosols: Global Climatology and Radiative Characteristics, ISBN: 0-937194-22-0, 1991.

Ansmann, A., Wandinger, U., Riebesell, M., Weitkamp, C., and Michaelis, W.: Independent measurement of extinction and backscatter profiles in cirrus clouds by using a combined Raman elastic-backscatter lidar, Appl. Opt. 31, 7113-7113, 1992.

Bailey, M. and Hallett, J.: Nucleation effects on the habit of vapour grown ice crystals from -18 to $-42{ }^{\circ} \mathrm{C}$, Q. J. Roy. Meteorol. Soc., 128, 1461-1483, 2002.

Bergeron, T.: On the physics of cloud and precipitation, Proceedings 5th Assembly U.G.G.I., Lisbon, Portugal, 156-178, 1935.

Blanchet, J.-P. and List, R.: Estimation of optical properties of Arctic haze using a numerical model, Atmos. Ocean., 21, 444-464, 1983.

Böckmann, C.: Hybrid regularization method for the ill-posed inversion of multiwavelength lidar data to determine aerosol size distribution, Appl. Opt., 40, 1329-1342, 2001.

Boers, R., Spinhirne, J. D., and Hart, W. D.: Lidar Observations of the Fine-Scale Variability of Marine Stratocumulus Clouds, J. Appl. Meteorol., 27, 797-810, 1988.

Boudala, F. S., Isaac, G. A., Cober, S. G., and Fu, Q.: Liquid fraction in stratiform mixed- phase clouds from in situ observations, Q. J. Roy. Meteorol. Soc., 130, 2919-2931, 2004.

Campbell, J. R. and Shiobara, M.: Glaciation of a mixed-phase boundary layer cloud at a coastal arctic site as depicted in continuous lidar measurements, Polar Sci., 2, 121-127, 2008.

Chen, W. N., Chiang, C. W., and Nee, J. B.: Lidar ratio and depolarisation ratio for cirrus clouds, Appl. Opt., 31, 6470-6476, 2002. 
Chen, C. C., Hakim, G. J., and Durran, D. R.: Transient mountain waves and their interaction with large scales, J. Atmos. Scie., 64, 7, 2378-2400, 2007.

Christensen, J. H., Christensen, O. B., Lopez, P., van Mijgaard, E., and Botzet, M.: The HIRHAM4 regional atmospheric climate model, DMI Science Rep. 96-4, 1-51, 1996.

Collins, W. D., Bitz, C. M., Blackmon, M. L., Bonan, G. B., Bretherton, C. S., Carton, J. A., Chang, P., Doney, S. C., Hack, J. J., Henderson, T. B., Kiehl, J. T., Large, W. G., McKenna, D. S., Santer, B. D., and Smith, R. D.: The Community Climate System Model: CCSM3, J. Climate, 19, 2122-2143, 2006.

Curry, J. A., Schramm, J. L., and Ebert, E. E.: Impact of Clouds on the Surface Radiation Balance of the Arctic Ocean, Meteorol. Atmos. Phys., 51, 197-217, 1993.

Curry, J. A., Rossow, W. B., Randall, D., and Schramm, J. L.: Overview of Arctic Cloud and Radiation Characteristics, Journal of Climate, 9, 1731-1764, 1996.

Curry, J. A., Pinto, J. O., Benner, T., and Tschudi, M.: Evolution of the cloudy boundary layer during the autumnal freezing of the Beaufort Sea, J. Geophys. Res., 102(D12), 13851-13860, 1997.

Curry, J. A., Hobbs, P. V., King, M. D., Randall, D. A., Minnis, P., Isaac, G. A., Pinto, J. O., Uttal, T., Bucholtz, A., Cripe, D. G., Gerber, H., Fairall, C. W., Garrett, T. J., Hudson, J., Intrieri, J. M., Jakob, C., Jensen, T., Lawson, P., Marcotte, D., Nguyen, L., Pilewskie, P., Rangno, A., Rogers, D. C., Strawbridge, K. B., Valero, F. P. J., Williams, A. G., and Wylie, D.: FIRE Arctic Clouds Experiment, B. Am. Meteorol. Soc., 81, 1, 5-29, 2000.

Dörnbrack, A., Stachlewska, I.S., Ritter, C., and Neuber, R.: Aerosol distribution around Svalbard during intense easterly winds, Atmos. Chem. Phys., 10, 1473-1490, 2010, http://www.atmos-chem-phys.net/10/1473/2010/.

Draxler, R. R. and Hess, G. D.: An Overview of the Hysplit_4 Modeling System for Trajectories, Dispersion, and Deposition, Aust. Meteor. Mag., 47, 295-308, 1998.

Dye, J. E. and Baumgardner, D.: Evaluation of the Forward Scattering Spectrometer Probe. Part I: Electronic and optical studies, J. Atmos. Oceanic Technol., 1, 329-344, 1984.

Ehrlich, A., Bierwirth, E., Wendisch, M., Gayet, J.-F., Mioche, G., Lampert, A., and Heintzenberg, J.: Cloud phase identification of Arctic boundary-layer clouds from airborne spectral reflection measurements: test of three approaches, Atmos. Chem. Phys., 8, 7493-7505, 2008, http://www.atmos-chem-phys.net/8/7493/2008/.

Ehrlich, A., Wendisch, M., Bierwirth, E., Gayet, J.-F., Mioche, G., Lampert, A., and Mayer, B.: Evidence of ice crystals at cloud top of Arctic boundary-layer mixed-phase clouds derived from airborne remote sensing, Atmos. Chem. Phys., 9, 9401-9416, 2009, http://www.atmos-chem-phys.net/9/9401/2009/.

Ehrlich, A.: The Impact of Ice Crystals on Radiative Forcing and Remote Sensing of Arctic Boundary-Layer Mixed-Phase Clouds, PhD thesis, http://ubm.opus.hbz-nrw.de/frontdoor.php? source_opus=2001, 2009.

Findeisen, W.: Kolloidmeteorologische Vorgänge bei Niederschlagsbildung, Meteor. Z., 55, 121-133, 1938.

Fitzgerald, J. W: Approximation formulas for the equilibrium size of an aerosol particle as a function of its dry size and composition and the ambient relative humidity, J. Appl. Meteorol., 14, 6, 1044-1049, 1975.
Gayet, J.-F., Crépel, O., Fournol, J. F., and Oshchepkov, S.: A new airborne polar Nephelometer for the measurements of optical and microphysical cloud properties. Part I: Theoretical design, Ann. Geophys., 15, 451-459, 1997, http://www.ann-geophys.net/15/451/1997/.

Gayet, J.-F., Asano, S., Yamazaki, A., Uchiyama, A., Sinyuk, A., Jourdan, O., and Auriol, F.: Two case studies of winter continental-type water and mixed-phase stratocumuli over the sea 1. Microphysical and optical properties, J. Geophys. Res., 107(D21), 4569, doi:10.1029/2001JD001106, 2002.

Gayet J.-F., Stachlewska, I. S., Jourdan, O., Shcherbakov, V., Schwarzenboeck, A., and Neuber, R.: Microphysical and optical properties of precipitating drizzle and ice particles obtained from alternated Lidar and in situ measurements, Ann. Geophys., 25, 1487-1497, 2007, http://www.ann-geophys.net/25/1487/2007/.

Gayet, J.-F., Mioche, G., Dörnbrack, A., Ehrlich, A., Lampert, A., and Wendisch, M.: Microphysical and optical properties of Arctic mixed-phase clouds. The 9 April 2007 case study, Atmos. Chem. Phys., 9, 6581-6595, 2009,

http://www.atmos-chem-phys.net/9/6581/2009/.

Giannakaki, E., Balis, D. S., Amiridis, V., and Kazadzis, S.: Optical and geometrical characteristics of cirrus clouds over a midlatitude lidar station, Atmos. Chem. Phys., 7, 5519-5530, 2007, http://www.atmos-chem-phys.net/7/5519/2007/.

Haag, W. and Kärcher, B.: The impact of aerosol and gravity waves on cirrus clouds in midlatiudes, J. Geophys. Res., 109, D12202, doi:10.1029/2004JD004579, 2004.

Harrington, J. Y., Reisin, T., Cotton, W. R., and Kreidenweis, S. M.: Cloud resolving simulations of Arctic stratus, Part II: Transitionseason clouds, Atmos. Res., 51, 45-75, 1999.

Herber, A., Thomason, L. W., Gernandt, H., Leiterer, U., Nagel, D., Schulz, K.-H., Kaptur, J., Albrecht, T., and Notholt, J., Continuous day and night aerosol optical depths observations in the Arctic between 1991 and 1999, J. Geophys Res., 107(D10), 4097, doi:10.1029/2001JD000536, 2002.

Hobbs, P. V., Rangno, A. L., Shupe, M., and Uttal, T.: Airborne studies of cloud structures over the Arctic Ocean and comparison with retrievals from ship-based remote sensing measurements, J. Geophys. Res., 106(D14), 15029-15044, 2001.

Hoffmann, A., Ritter, C., Stock, M., Shiobara, M., Lampert, A., Maturilli, M., Orgis, T., Neuber, R., and Herber, A.: Ground-based lidar measurements from Ny-Ålesund during ASTAR 2007, Atmos. Chem. Phys., 9, 9059-9081, 2009, http://www.atmos-chem-phys.net/9/9059/2009/.

Hu, Y., Winker, D., Yang, P., Baum, B., Poole, L., and Vann, L.: Identification of cloud phase from PICASSO-CENA lidar depolarization: a multiple scattering sensitivity study, J. Quant. Spectrosc. Radiat. T., 70, 569-579, 2001.

Hu, Y., Liu, Z., Winker, D., Vaughan, M., and Noel, V.: Simple relation between lidar multiple scattering and depolarization for water clouds, Opt. Lett., 31, 12, 1809-1811, 2006.

Hu, Y., Vaughan, M., Liu, Z., Lin, B., Yang, P., Flittner, D., Hunt, B., Kuehn, R., Huang, J., Wu, D., Rodier, S., Powell, K., Trepte, C., and Winker, D.: The depolarization - attenuated backscatter relation: CALIPSO lidar measurements vs. theory, Opt. Exp., 15, 9, 5327-5332, 2007. 
van de Hulst, H. C.: Light scattering by small particles, New York, Dover, ISBN: 0486642283, 1981.

Inoue, J., Liu, J., Pinto, J. O., and Curry, J. A.: Intercomparison of Arctic Regional Climate Models: Modeling Clouds and Radiation for SHEBA in May 1998, J. Clim., 19, 4167-4178, 2006.

Intrieri, J. M., Shupe, M. D., Uttal, T., and McCarty, B. J.: An annual cycle of Arctic cloud characteristics observed by radar and lidar at SHEBA, J. Geophys. Res., 107(C10), 8030, doi:10.1029/2000JC000423, 2002a.

Intrieri, J. M., Fairall, C. W., Shupe, M. D., Persson, P. O. G., Andreas, E. L., Guest, P. S., and Moritz, R. E.: An annual cycle of Arctic surface cloud forcing at SHEBA, J. Geophys. Res., 107(C10), 8039, doi:10.1029/2000JC000439, 2002b.

Intrieri, J. M. and Shupe, M. D.: Characteristics and radiative effects of diamond dust over the western Arctic Ocean region, J. Climate, 17(15), 2953-2960, 2004.

IPCC, Intergovernmental Panel on Climate Change: Climate Change 2007: The Physical Science Basis. Contribution of Working Group I to the Fourth Assessment Report of the Intergovernmental Panel on Climate Change, edited by: Solomon, S., Qin, D., Manning, M., Chen, Z., Marquis, Z. M., Averyt, K. B., Tignor M., and Miller, H. L., Cambridge University Press, 996 pp., 2007.

Ishii, S., Shibata, T., Nagai, T., Mizutani, K., Itabe, T., Hirota, M., Fujimoto, T., and Uchino, O.: Arctic haze and clouds observed by lidar during four winter seasons of 1993-1997, at Eureka, Canada, Atmospheric Environment, 33, 2459-2470, 1999.

Jiang, H., Cotton, W. R., Pinto, J. O., Curry, J. A., and Weissbluth, M. J: Cloud Resolving Simulations of Mixed-Phase Arctic Stratus Observed during BASE: Sensitivity to Concentration of Ice Crystals and Large-Scale Heat and Moisture Advection, J. Atmos. Sci., 57, 2105-2117, 2000.

Jourdan, O., Oshchepkov, S., Shcherbakov, V., Gayet, J.-F., and Isaka, H.: Assessment of cloud optical parameters in the solar region: Retrievals from airborne measurements of scattering phase functions, J. Geophys. Res., 108(D18), 4572, doi:10.1029/2003JD003493, 2003.

Kay, J. E., L'Ecuyer, T., Gettelman, A., Stephens, G., and O’Dell, C.: The contribution of cloud and radiation anomalies to the 2007 Arctic sea ice extent, Geophys. Res. Lett., 35, L08503, doi:10.1029/2008GL033451, 2008.

Key, E. L., Minnett, P. J., and Jones, R. A.: Cloud distributions over the coastal Arctic Ocean: surface-based and satellite observations, Atmos. Res., 72, 57-88, 2004.

Klett, J. D.: Lidar inversions with variable backscatter/extinction values, Appl. Opt., 24, 1638-1648, 1985.

Kirsche, A: Regularisierungsverfahren: Entwicklung, Konvergenzuntersuchung und optimale Anpassung für die Fernerkundung, PhD thesis, University Potsdam, Germany, 2008.

Kirsche, A. and Böckmann, C.: Pade iteration method for regularization, Appl. Math. Comput., 180, 648-663, 2006.

Korolev, A., Isaac, G. A., and Hallett, J.: Ice particle habits in stratiform clouds, Q. J. Roy. Meteorol. Soc., 126, 2873-2902, 2000.

Korolev, A., and Isaac, G.: Phase transformation of mixed-phase clouds, Q.J.R. Meteorol. Soc.129, 19-38, 2003.

Korolev, A. V., Isaac, G. A., Cober, S. G., Strapp, J. W., and Hallett, J.: Microphysical characterization of mixed-phase clouds, Q. J. Roy. Meteor. Soc., 129, 39-65, 2003.
Korolev, A. and Field, P. R.: The effect of dynamics on mixed-phase clouds: Theoretical considerations, J. Atmos. Sci., 65, 66-86, 2008.

Kupfer, H., Herber, A., and König-Langlo, G.: Radiation Measurements and Synoptic Observations at Ny-Ålesund, Reports on Polar Research, 538, 75, http://epic.awi.de/Publications/Kup2006a. pdf, 2006.

Lampert, A., Ehrlich, A., Dörnbrack, A., Jourdan, O., Gayet, J.F., Mioche, G., Shcherbakov, V., Ritter, C., and Wendisch, M.: Microphysical and Radiative Characterization of a Subvisible Midlevel Arctic Ice Cloud by Airborne Observations - A Case Study, Atmos. Chem. Phys., 9, 2647-2661, 2009, http://www.atmos-chem-phys.net/9/2647/2009/.

Law, K. S., Ancellet, G., Pelon, J., Turquety, S., Clerbaux, C., Pommier, M., de Villiers, R., Gayet, J.-F., Schwarzeboeck, A., Nedelec, P., Schneider, J., and Borrmann, S.: POLARCAT-France Airborne Experiment: first results. /Intern. Global Atmospheric Chemistry conference (IGAC), 7-12 September 2008, Annecy, France, 2008.

Lawson, P., Heymsfield, A. J., Aulenbach, S. M., and Jensen, T. L.: Shapes, sizes and light scattering properties of ice crystals in cirrus and a persistent contrail during SUCCES, Geophys. Res. Lett., 25, 1331-1334, 1998.

Lawson, R. P., Baker, B. A., and Schmitt, C. G.: An overview of microphysical properties of Arctic clouds observed in May and July 1998 during FIRE ACE, J. Geophys. Res., 106(D14), 1498915014, 2001.

Lesins, G., Bourdages, L., Duck, T. J., Drummond, J. R., Eloranta, E. W., and Walden, V. P.: Large surface radiative forcing from topographic blowing snow residuals measured in the High Arctic at Eureka, Atmos. Chem. Phys., 9, 1847-1862, 2009, http://www.atmos-chem-phys.net/9/1847/2009/.

Luo, Y., Xu, K.-M., Morrison, H., McFarquhar, G. M., Wang, Z., and Zhang, G.: Multi-layer arctic mixed-phase clouds simulated by a cloud-resolving model: Comparison with ARM observations and sensitivity experiments, J. Geophys. Res., 113, D12208, doi:10.1029/2007JD009563, 2008.

McFarquhar, G. M. and Cober, S. G.: Single Scattering Properties of Mixed Phase Arctic Clouds at Solar Wavelengths: Impact on radiative transfer, J. Climate, 17, 19, 3799-3813, 2004.

McFarquhar, G. M., Zhang, G., Poellot, M. R., Kok, G. L., McCoy, R., Tooman, T., Fridlind, A., and Heymsfield, A. J.: Ice properties of single-layer stratocumulus during the Mixed-Phase Arctic Cloud Experiment: 1. Observations, J. Geophys. Res., 112, D24201, doi:10.1029/2007JD008633, 2007.

Morrison, H., Pinto, J. O., Curry, J. A., and McFarquhar, G. M.: Sensitivity of modeled Arctic mixed-phase stratocumulus to cloud condensation and ice nuclei over regionally varying surface conditions, J. Geophys. Res., 113, D05203, doi:10.1029/2007JD008729, 2008.

Nakajima, T. and King, M.: Determination of the optical thickness and effective particle radius of clouds from reflected solar radiation measurements. Part I: Theory, J. Atmos. Sci., 47, 18781893, 1990.

Nicolas, F., Bissonnette, L. R., and Flamant, P. H.: Lidar effective multiple-scattering coefficients in cirrus clouds, Appl. Opt., 36(15), 3458-3468, 1997.

Oshchepkov, S. L., Isaka. H., Gayet, J. F., Sinyuk, A., Auriol, F., and Havemann, S.: Microphysical properties of mixed-phase \& 
ice clouds retrieved from in situ airborne "Polar Nephelometer" measurements, Geophys. Res. Lett., 27, 209-213, 2000.

Pinto, J.: Autumnal Mixed-Phase Cloudy Boundary Layers in the Arctic, J. Atmos. Sci., 55, 2016-2037, 1998.

Pinto, J. O., Curry, J. A., and Intrieri, J. M.: Cloud-aerosol interactions during autumn over Beaufort Sea, J. Geophys. Res., 106(D14), 15077-15097, 2001.

Pornsawad, P., Böckmann, C., Ritter, C., and Rafler, M.: Ill-posed retrieval of aerosol extinction coefficient profiles from Raman lidar data by regularization, Appl. Opt., 47, 1649-1661, 2008.

Quinn, P. K., Shaw, G., Andrews, E., Dutton, E. G., Ruoho-Airola, T., and Gong, S. L.: Arctic haze: Current trends and knowledge gaps, Tellus, 59B, 99-114, 2007.

Rauber, R. M., and Tokay, A.: An Explanation for the Existence of Supercooled Water at the Top of Cold Clouds, J. of Atmos. Sciences, 48, 8, 1005-1023, 1991.

Reichardt, J., Reichardt, S., Hess, M., and McGee, T. J.: Correlations among the optical properties of cirrus-cloud particles: Microphysical interpretation, J. Geophys. Res., 107(D21), 4562, doi:10.1029/2002JD002589, 2002.

Richter, A., Gayet, J.-F., Mioche, G., Ehrlich, A., and Dörnbrack, A.: Mixed-Phase Clouds in the Arctic: A Synopsis of Airborne Lidar, In-Situ, and Albedometer Observations, complemented by Meteorological Analyses. 24th International Laser Radar Conference (ILRC), 23-27 June 2008, Boulder, CA, USA, 881-884, 2008.

Rinke, A., Dethloff, K., and Fortmann, M.: Regional climate effects of Arctic Haze, Geophys. Res. Lett., 31, L16202, doi:10.1029/2004GL020318, 2004.

Ritter, C., Kirsche, A., and Neuber, R.: Tropospheric Aerosol characterized by a Raman Lidar over Spitsbergen, Proceedings of the 22nd International Laser Radar Conference (ILRC2004), ESA SP-561, 459-462, 2004.

Sandvik, A., Biryulina, M., Kvamstø, N. G., Stamnes J. J., and Stamnes, K.: Observed and simulated composition of Arctic clouds: Data properties and model validation, J. Geophys. Res., 112, D05205, doi:10.1029/2006JD007351, 2007.

Sassen, K., Griffin, M. K., and Dodd, G. C.: Optical Scattering and Microphysical Properties of Subvisual Cirrus Clouds, and Climatic Implications, J. Appl. Meteorol., 28, 91-98, 1989.

Sassen, K.: The polarization lidar technique for cloud research: A review and current assessment, B. Am. Meteorol. Soc., 71, 18481866, 1991.

Sassen, K. and Comstock, J.: A Midlatitude Cirrus Cloud Climatology from the Facility for Atmospheric Remote Sensing. Part III: Radiative Properties, J. Atmos. Sci., 58, 2113-2127, 2001.

Sassen, K: Identifying Atmospheric Aerosols with Polarization Lidar, Advanced Environmental Monitoring, Chap. 10, edited by: Kim, Y. J. and Platt, U., Springer, The Netherlands, doi:10.1007/978-1-4020-6364-0, ISBN: 978-1-40206363-3, 2008.

Scheuer, E., Talbot, R. W., Dibb, J. E., Seid, G. K., and DeBell, L.: Seasonal distributions of fine aerosol sulfate in the North American Arctic basin during TOPSE, J. Geophys. Res. 108(D4), 8370 doi:10.1029/2001JD001364, 2003.

Shaw, G. E.: Aerosol Chemical Components in Alaska Air Masses 2. Sea Salt and Marine Product, J. Geophys. Res., 96(D12), 22369-22372, 1991.

Shiobara, M., Yabuki, M., and Kobayashi, H.: A polar cloud anal- ysis based on Micro-pulse Lidar measurements at Ny-Alesund, Svalbard and Syowa, Antarctica, Phys. Chem. Earth, 28, 12051212, 2003.

Shupe, M. D. and Intrieri, J. M.: Cloud radiative forcing of the Arctic surface: The influence of cloud properties, surface albedo and solar zenith angle, J. Climate, 17, 616-628, 2004.

Shupe, M. D., Kollias, P., Persson, P. O. G., and McFarquhar, G. M.: Vertical Motions in Arctic Mixed-Phase Stratiform Clouds, J. Atmos. Sci., 65, 1304-1322, 2008.

Spinhirne, J. D.: Micro pulse lidar, IEEE T. Geosci. Remote Sens., 31, 48-55, 1993.

Stachlewska, I. S., Wehrle, G., Stein, B., Neuber, R.: Airborne Mobile Aerosol Lidar for measurements of Arctic aerosols, Proceedings of the 22nd International Laser Radar Conference (ILRC2004), ESA SP-561, 1, 87-89, 2004.

Stachlewska, I., Neuber, R., Lampert, A., Ritter, C., and Wehrle, G: AMALi - the Airborne Mobile Aerosol Lidar for Arctic research, Atmos. Chem. Phys. Discuss., 9, 18745-18792, 2009, http://www.atmos-chem-phys-discuss.net/9/18745/2009/.

Stohl, A.: Characteristics of atmospheric transport into the Arctic troposphere, J. Geophys. Res, 111, D11306, doi:10.1029/2005JD006888, 2006.

Ström, J., Umegård, J., Tørseth, K., Tunved, P., Hansson, H.-C., Holmén, K., Wismann, V., Herber, A., and König-Langlo, G.: One year of particle size distribution and aerosol chemical composition measurements at the Zeppelin Station, Svalbard, March 2000-March 2001, Phys. Chem. Earth, 28, 1181-1190, 2003.

Tomasi, C. and Tampieri, F.: Size distribution models of small water droplets in mist and their volume extinction coefficients at visible and infrared wavelengths, Atmos. Environ., 10, 1005-1013, 1976.

Turner, D. D.: Arctic Mixed-Phase Cloud Properties from AERI Lidar Observations: Algorithm and Results from SHEBA, J. Appl. Meteo., 44, 427-444, 2005.

Vavrus, S.: The impact of cloud feedbacks on Arctic Climate under greenhouse forcing, Jour. of Climate, 17, 3, 603-615, 2004.

Verlinde, J., Harrington, J. Y., McFarquhar G. M., et al.: The Mixed-Phase Arctic Cloud Experiment (M-PACE), B. Am. Meteorol. Soc., 88, 205-221, 2007.

Wandinger, U, Müller, D, Böckmann, C., Althausen, D., Matthias, V, Bösenberg, J, Weiss, V, Fiebig, M, Wendisch, M., Stohl, A., and Ansmann, A: Optical and microphysical characterization of biomass-burning and industrial-pollution aerosols from multiwavelength lidar and aircraft measurements, J. Geophys. Res. Atmos., 107(D21), 8125, doi:10.1029/2000JD000202, 2002.

Wegener, A.: Thermodynamik der Atmosphäre, J. A. Barth Verlag, 311 pp., 1911.

Welton, E. J., Campbell, J. R., Spinhirne, J. D., and Scott, V. S.: Global monitoring of clouds and aerosols using a network of micro-pulse lidar systems, Proc. Int. Soc. Opt. Eng., 4153, 151$158,2001$.

Wendisch, M., Müller, D., Schell, D., and Heintzenberg, J.: An airborne spectral albedometer with active horizontal stabilization, J. Atmos. Ocean. Technol., 18, 1856-1866, 2001.

Wyser, K., Jones, C. G., Du, P., Girard, E., Willén, U., Cassano, J., Christensen, J. H., Curry, J. A., Dethloff, K., Haugen, J.-E., Jacob, D., Køltzow, M., Laprise, R., Lynch, A., Pfeifer, S., Rinke, A., Serreze, M., Shaw, M. J., Tjernström, M., and Zagar, M.: An evaluation of Arctic cloud and radiation processes during the 
SHEBA year: simulation results from eight Arctic regional climate models, Clim. Dynam., 30, 203-223, 2008.

Wyser, K. and Jones, C. G.: Modeled and observed clouds during Surface Heat Budget of the Arctic Ocean (SHEBA), J. Geophys. Res., 110, D09207, doi:10.1029/2004JD004751, 2005.
You, Y., Kattawar, G. W., Yang, P., Hu, Y. X., and Baum, B. A.: Sensitivity of depolarized lidar signals to cloud and aerosol particle properties, J. Quant. Spectrosc. Radiat. T., 100, 470-482, 2006. 